\title{
Design, Build and Fly a Flying Wing
}

\author{
By Ahmed A. Hamada* \\ Abdelrahman A. Sultan ${ }^{\dagger}$ \\ Mohamed M. Abdelrahman
}

This research represents one of the graduation projects for the final year of undergraduate students in Aerospace Engineering Department for the academic year 2015-2016. The objective of the present paper is to design, build and test a flying wing. The purpose of this work is to describe the methodology and decision making involved in the process of designing a flying wing. First, the design is based on the design theories and followed by performance, stability analysis, and motion simulation. The wind-tunnel tests are performed to compare theoretical results based on design with the experimental measured results. Finally, a real flight test is performed to achieve the objective of the project.

Keywords: CFD, Flight Simulation, Flying Wing, Performance, Stability, UAV, Winglets, Wind Tunnel Test.

\section{Introduction}

A flying wing is a tailless fixed-wing aircraft that has no definite fuselage. Theoretically, flying wings have the most efficient aircraft configurations from the aerodynamic point of view and structural weight. An advantage of the tailless aircraft is the high lift to drag ratio. The main disadvantage of the flying wings is the lack of stability which has to be compensated by adding more design restrictions to the wing design. However, it is a good opportunity to dive into the flying wing design process with all its problems and challenges.

The design methodology follows an engineering design process starting by setting the target mission specifications of the design. Then, a statistical analysis of other flying wings data of similar mission specifications is performed. After that, a preliminary design is performed by studying the variation of the geometrical parameters and their effects over the design requirements: lift, drag and moment, to conclude with a near optimum preliminary design. This preliminary design undergoes aerodynamic analyses by different programs and methods. Moreover, a wind-tunnel test is applied to compare with the theoretical aerodynamic results. Furthermore, a detailed design stage is carried out by choosing a light, modernused material and drawing the design using CAD program to fabricate the flying wing. Static and dynamic stability analyses are performed by XFLR5program (Drela and Youngren, 2000). Codes are built on Matlab program to simulate the flying wing behaviour over certain trajectories. Next, a performance analysis is utilized to make sure the mission specifications are reached. Finally,

\footnotetext{
${ }^{*}$ B.Sc. Student, Cairo University, Egypt.

'B.Sc. Student, Cairo University, Egypt.

${ }^{\ddagger}$ Professor, Cairo University, Egypt.
} 
the flying wing is manufactured and a flight test is carried to check the real-life performance. Figure 1 summarizes the design methodology.

Figure 1. Design Methodology

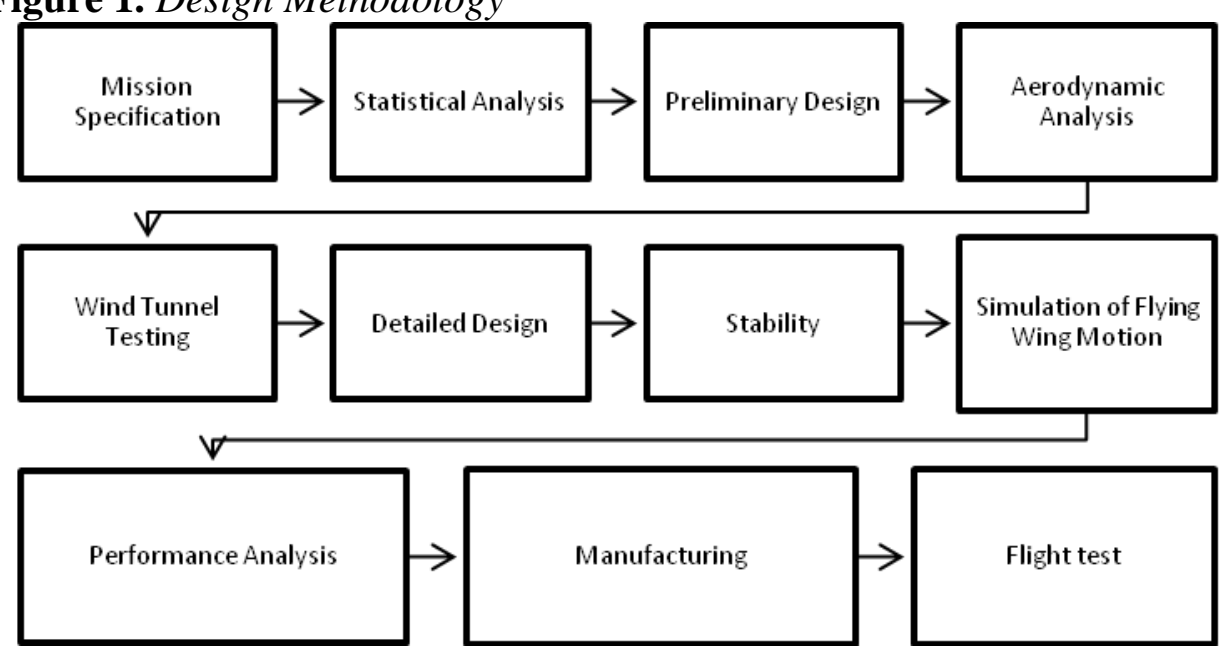

The hypothetical evolution of a sweptback tailless aircraft from a tailed aircraft starts from sweeping back both the straight wing and the horizontal stabilizer. Then, the stabilizer was cut into two halves and they were merged to the wingtips. In this position they have, with respect to the center of the gravity, the same moment arm as before and because of this one would not expect their stabilizing effect to be reduced. The action of the elevator should therefore be the same as before. The rudder can be split into two halves and attached to the wingtips as outboard fins or "winglets". In the latter case, fuselage as a support for tail unit can be eliminated or at least considerably reduced in size. The hypothetical emergence of the reflex airfoil sections starts from elongating the tail plane of tailed aircraft until it has the same span as the main wing and reducing its distance from the main wing until it is merged with the trailing edge of the main wing. By doing this, the effective angle of incidence between the profiles of the tail plane and of the wing is increased. This compensates for the reduction in elevator moment arm. Fusion of the two profiles produces the typical "double curved" or "S" shape of the so called reflex wing section. When viewed from the side, the front part of the profile is convex whilst the rear part is concave (Nickel and Wohlfahrt, 1994).

There are several advantages of flying wings. Briefly, mentioned, the weak directional stability gives spiral stability. Flying wings are stable while circling, i.e. they hold attitude with constant degree of bank without pilot movement of control stick. Normally, the stall behavior is good and the tendency to spin is low. A low drag coefficient is expected but not always attained. Theoretically, a flying wing should be less expensive to construct. Beside these advantages, there are some of disadvantages which should be compensated. The flight performance is often inferior. This stems from the desire to improve the stability and maneuverability. The permissible C.G. limits are smaller. The weak pitch damping 
and the small moment of inertia around the pitch axis may induce alphaoscillations. Cross-wind take offs and landings are difficult (Backstrorm, 1979).

\section{Mission Specification}

A specification that was agreed upon is that the flying wing should not be too small or too large. If the aircraft is too small, it becomes too sensitive and causes too many stability problems. On the other hand, if the aircraft is too large, manufacturing process becomes harder and might not be executable with available tools. The mission specifications can be summarized in Table 1 .

Table 1. Mission Specifications of the Design

\begin{tabular}{l|l}
\hline \hline Parameter & Value/Choice \\
\hline Propulsion System & Electric motor with propeller \\
Maximum payload weight & (Tiny camera) 100 grams \\
Endurance & 15 minutes \\
Range & 500 meters \\
\hline \hline
\end{tabular}

\section{Statistical Analysis}

During early design stages, the approach, introduced in the original reliable literature regarding aircraft design such as the "Airplane Design" (Roskam, 2003), is considered as the most widely used, so it was logical to follow his steps. This approach needed validation because it deals with conventional tailed aircrafts of different scale than that of the available flying wings in the market. The validation process is carried with the help of data from a previous flying wing graduation project carried in Cairo University (Hussein et al., 2010). The result is that this approach is not suitable for flying wing design. However, it is decided to follow a similar idea of collecting statistical data to help in the initial sizing of the flying wing. Statistical data are divided into four categories: mission specification, power plant, structure and material and finally electronics category.

Figures 2 and 3, show samples of the data collected after being plotted. Curve fitting is used to produce the shown curves. These fitted curves are used to get the first estimation of weight and speed of the design.

According to the curves obtained from the statistical data, if the span is chosen to be around 1.5 meters, it can be deduced that: the weight would turn out to be from 1 to $1.5 \mathrm{~kg}$ and the flight speed would be around $22-25 \mathrm{~m} / \mathrm{s}$. 
Figure 2. Span vs. Weight from Statistical Data

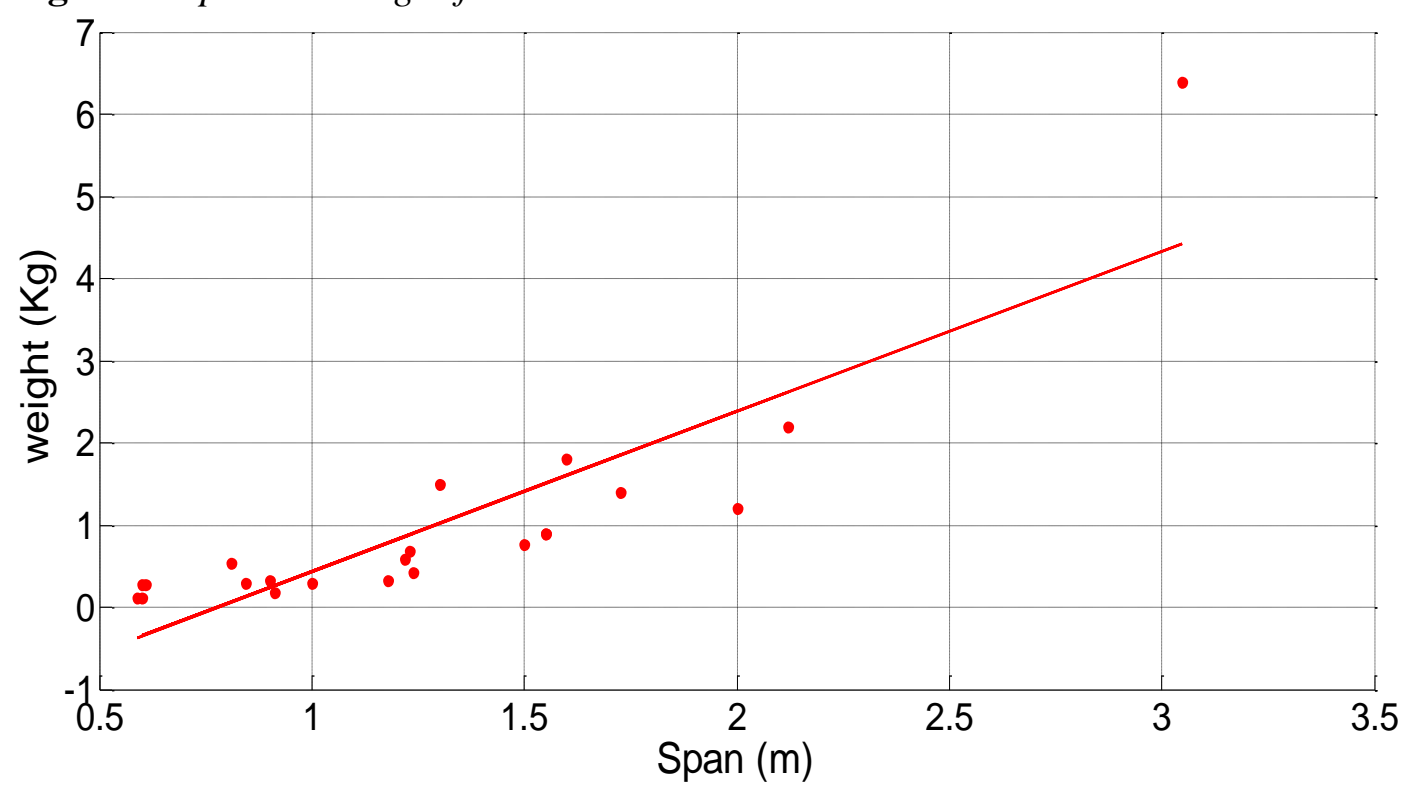

Figure 3. Speed vs. Span from Statistical Data

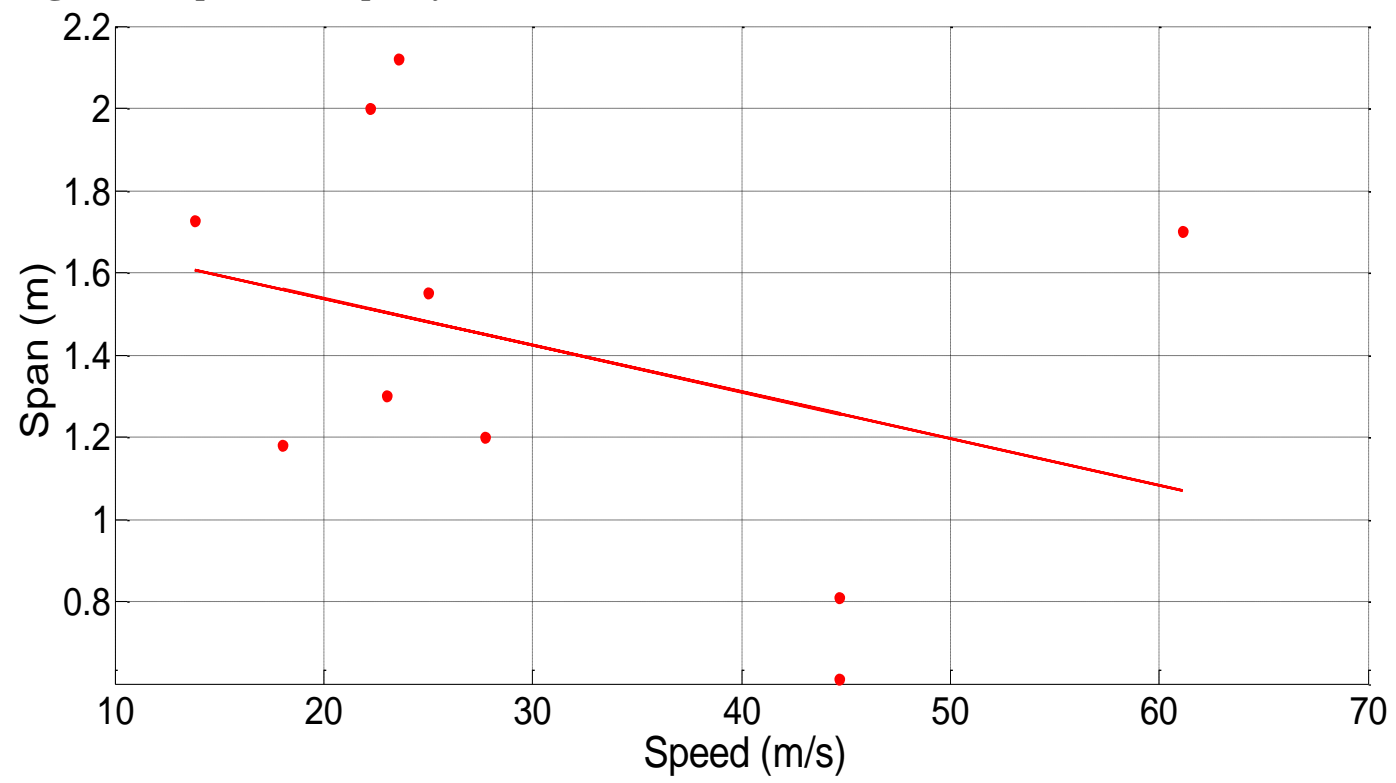

\section{Preliminary Design}

\section{Airfoil Selection}

For tailless aircraft, only airfoils with a small pitching moment should be used. If possible a zero pitching moment is preferable. So, the chosen airfoil is the HS522 airfoil, which is one of the most popular airfoils for swept wings due to low drag (speed) and very low Re-Numbers. This airfoil produces a nose down moment coefficient $\left(C_{m}\right)$. However, the moment coefficient $\left(C_{m}\right)$ is small 
compared to that of many other airfoils (Siegmann, 2017). HS522 airfoil shape is shown in Figure 4.

Figure 4. HS522 Airfoil Shape (Siegmann, 2017)

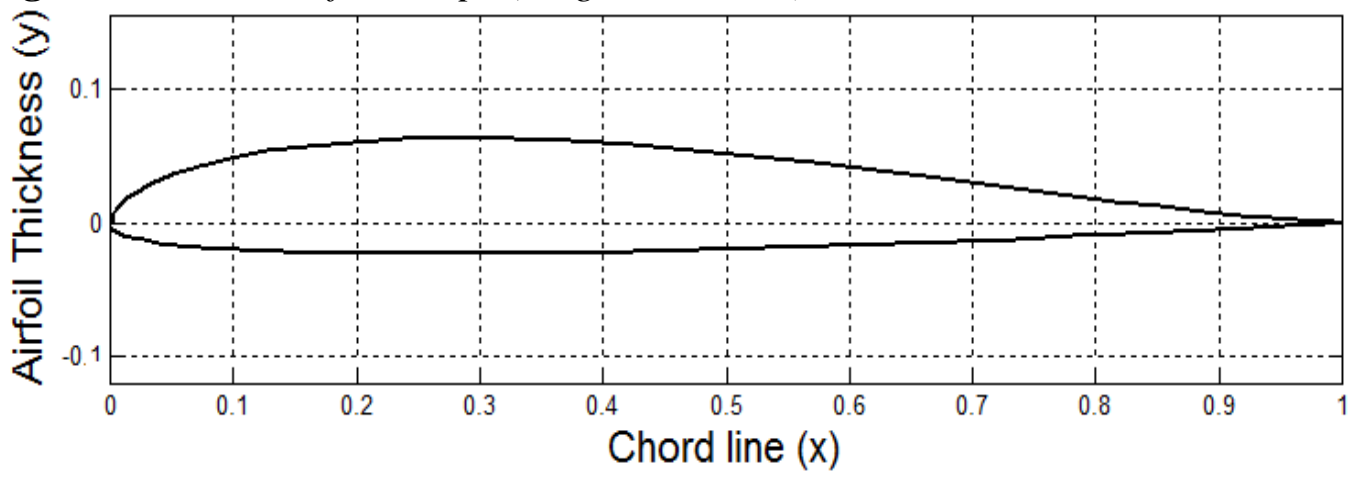

\section{Wing Planform Geometry Design}

Figure 5. Effect of Aspect Ratio on Lift Coefficient for Wing with Taper Ratio $=0.7$ and Sweep Back Angle $=18$

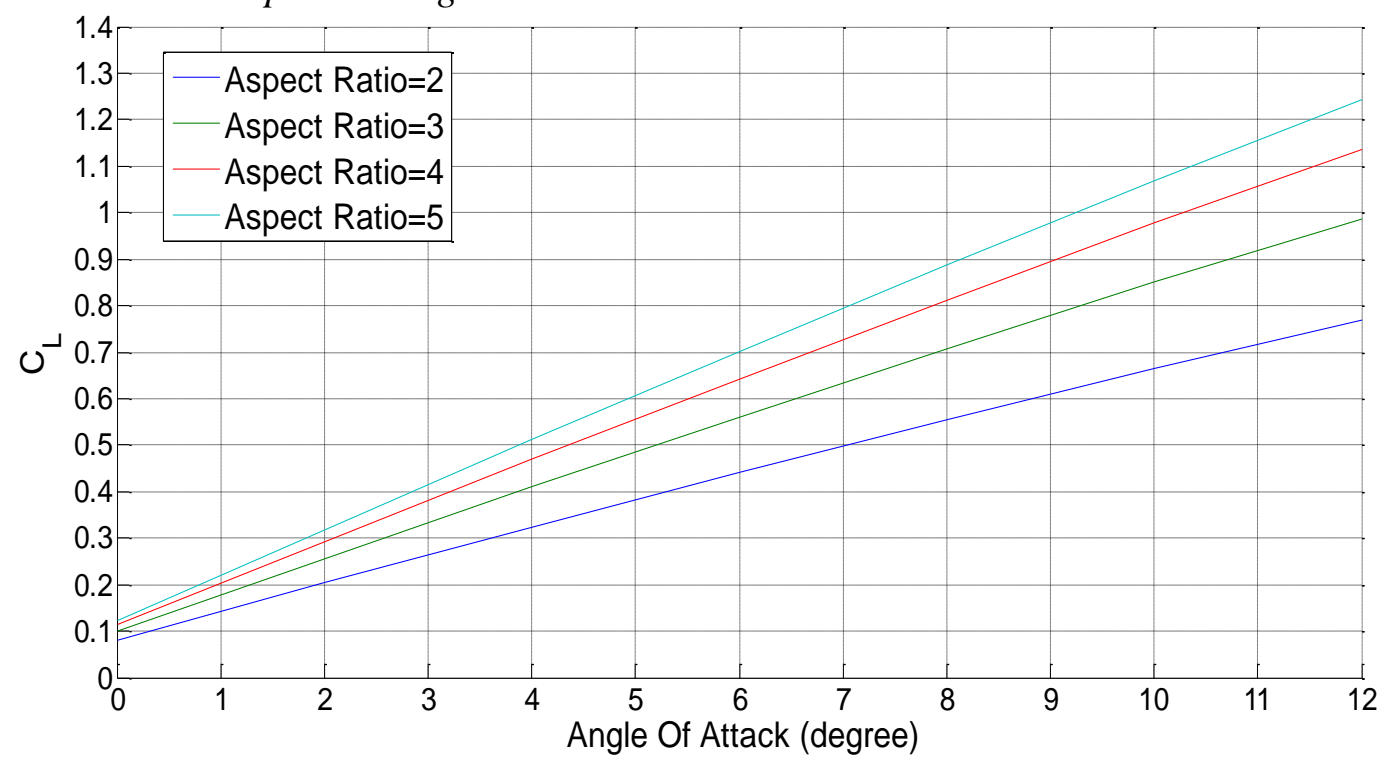

For every wing, there is a certain set of parameters that fully define its shape. Some of these parameters are: "aspect ratio, sweepback angle, taper ratio and span". And of course, there exists a large number of combinations for different choices of each parameter's value. So, in order to choose suitable values, the effect of changing each parameter on the lift, drag and moment is studied. Now, a cost function must be defined to obtain the optimum values of these parameters. The cost functions are maximum lift coefficient $\left(C_{L}\right)$, minimum drag coefficient $\left(C_{D}\right)$ and maximum negative slope of pitching moment coefficient with AOA $\left(C_{M_{\alpha}}\right)$. Seeking a near optimal design point, it is needed to observe the effect of 
each geometrical parameter while the other parameters are fixed on aerodynamic parameters. Results are obtained using panel method 3D which is generated by Matlab code (Abbas and Abdelrahman, 2015). A sample of these results is shown in Figures 5, 6 and 7 and all resulted figures can be shown in the B.Sc. graduation project, accomplished in Cairo University (Hamada and Sultan, 2016).

Figure 6. Effect of Taper Ratio on Drag Coefficient for Wing with Aspect Ratio $=2$ and Sweep Back Angle $=18$

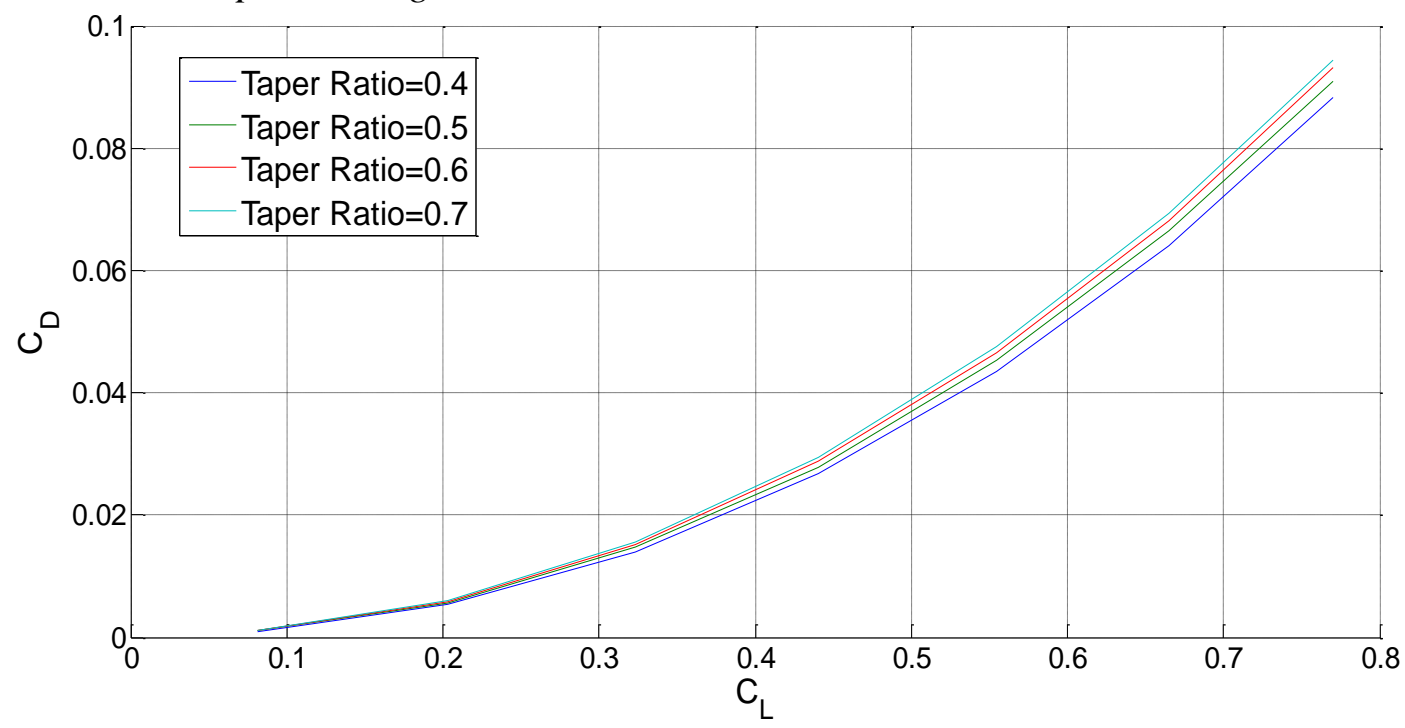

Figure 7. Effect of Sweep Back Angle on Pitching Moment Coefficient for Wing with Aspect Ratio $=2$ and Taper Ratio $=0.4$

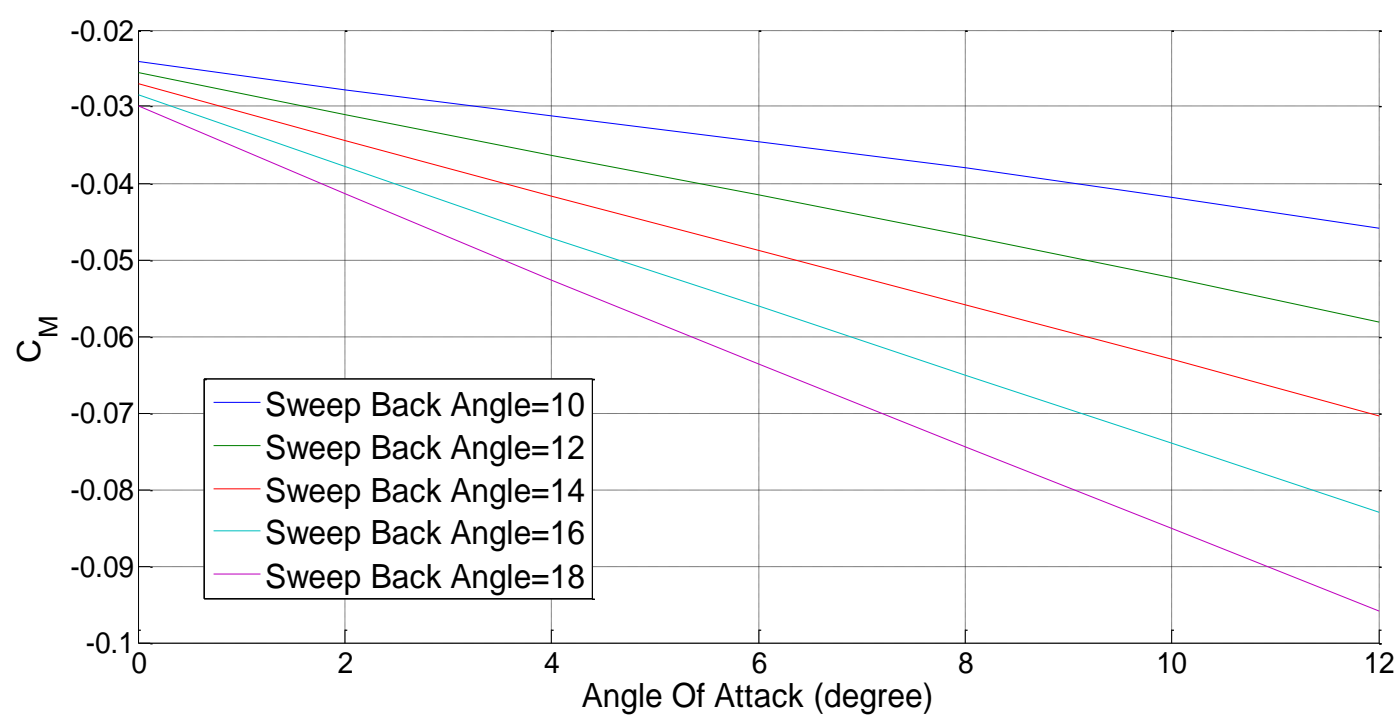

From the figures, it can be concluded that the effect of sweepback angle on lift and drag coefficient $\left(C_{L}, C_{D}\right)$ is negligible and as the sweepback angle increases, the negative slope of pitching moment coefficient with AOA $\left(C_{M_{\alpha}}\right)$ increases. Also, as the taper ratio increases, the lift coefficient $\left(C_{L}\right)$ slightly 
increases due to providing more lift at the tips. As it is known, there is an optimum value of taper ratio for minimum drag, which is around 0.4. The change in drag is small when the taper ratio is within the range of [0.2-0.7]. Moreover, as the taper ratio increases, the negative slope of pitching moment coefficient with AOA $\left(C_{M_{\alpha}}\right)$, increases. Furthermore, as the aspect ratio increases, lift coefficient $\left(C_{L}\right)$ increases for fixed span. The increase in lift coefficient $\left(C_{L}\right)$ decays as the aspect ratio increases. This ensures that the constraint of choosing airplane with moderate value of aspect ratio within range of [3-6] is reasonable for fixed span. In addition, the drag coefficient $\left(C_{D}\right)$ increases as aspect ratio increases until it reaches the value of 4 for fixed span. Then, the drag coefficient $\left(C_{D}\right)$ starts to decrease as aspect ratio increases after the value of 4 for fixed span. Besides, as the aspect ratio increases, the negative slope of pitching moment coefficient with AOA $\left(C_{M_{\alpha}}\right)$ rapidly increases for fixed span.

Hence, the near-optimum values of the geometrical parameters are that aspect ratio equals 5, taper ratio equals 0.7 and sweepback angle equals 30 degree to get maximum lift coefficient $\left(C_{L}\right)$, minimum drag coefficient $\left(C_{D}\right)$ and maximum negative slope of pitching moment coefficient with AOA $\left(C_{M_{\alpha}}\right)$.

\section{Control Surface Geometry Design}

Flying wings contain two main control surfaces, namely elevons and flaps. Elevons are located near wingtips and combine the functionality of the elevator and the aileron, while flaps are located in the wing center near the root chord. In designing control surfaces, Hussein et al., (2010) recommend the following.

Table 2. Recommendations for Control Surfaces (Hussein et al., 2010)

\begin{tabular}{ll}
\hline \hline Elevon design. \\
\hline $\begin{array}{l}\text { Elevon } \\
\text { chord. }\end{array}$ & $\begin{array}{l}\text { Equals } 50 \% \text { of local chord near wingtips. } \\
\text { Equals } 18 \% \text { for modern airfoils, or } 25 \% \text { for older airfoils of local chord } \\
\text { at the other side of elevon. }\end{array}$ \\
$\begin{array}{ll}\text { Elevon } \\
\text { length. }\end{array}$ & $\begin{array}{l}\text { If AR }>10, \text { elevator length is up to } 70 \% \text { of half-span. } \\
\text { Flap design }\end{array}$ \\
\hline Flap chord. & $\begin{array}{l}\text { Equals }(30-50) \% \text { of local chord at wing center near root chord. } \\
\text { Equals }(18-25) \% \text { of local chord at the other side of flap. }\end{array}$ \\
\hline \hline
\end{tabular}

Then, using an empirical relation, equation (1), mentioned in a stability text book (Nelson, 1998) and illustrated by Figure 8, to iterate on different sizes of the control surfaces: elevon and flap, a final design can be reached.

$$
\Delta \mathrm{C}_{L}=\frac{s_{t}}{s} \eta C_{\alpha_{\alpha_{t}}} \tau \delta_{e}
$$


Where $\Delta \mathrm{C}_{L}$ is the change in lift coefficient, $\frac{s_{t}}{S}$ is the ratio between the control surface area to the wing area, $\eta$ is the ratio between dynamic pressures, $C_{L_{\alpha_{t}}}$ is the elevator effectiveness, $\tau=\frac{d \alpha_{\mathrm{t}}}{d \delta_{\mathrm{t}}}$ and $\delta_{e}$ is the change in elevator deflection.

Figure 8. Flap Effectiveness Parameter (Nelson, 1998)

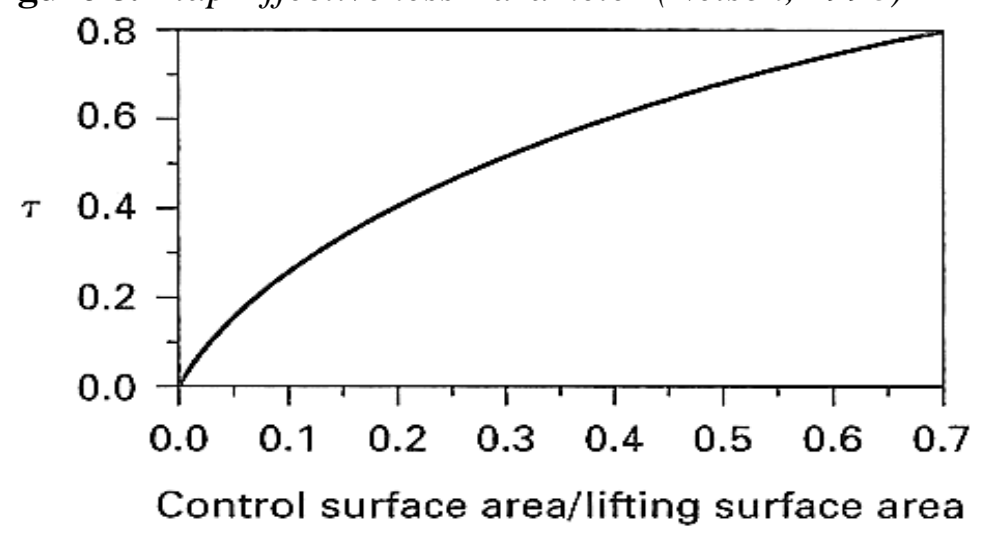

Figure 9 shows the flow chart of iteration procedure, followed in designing the control surface area.

Figure 9. Flow Chart of Iteration on Control Surface Area

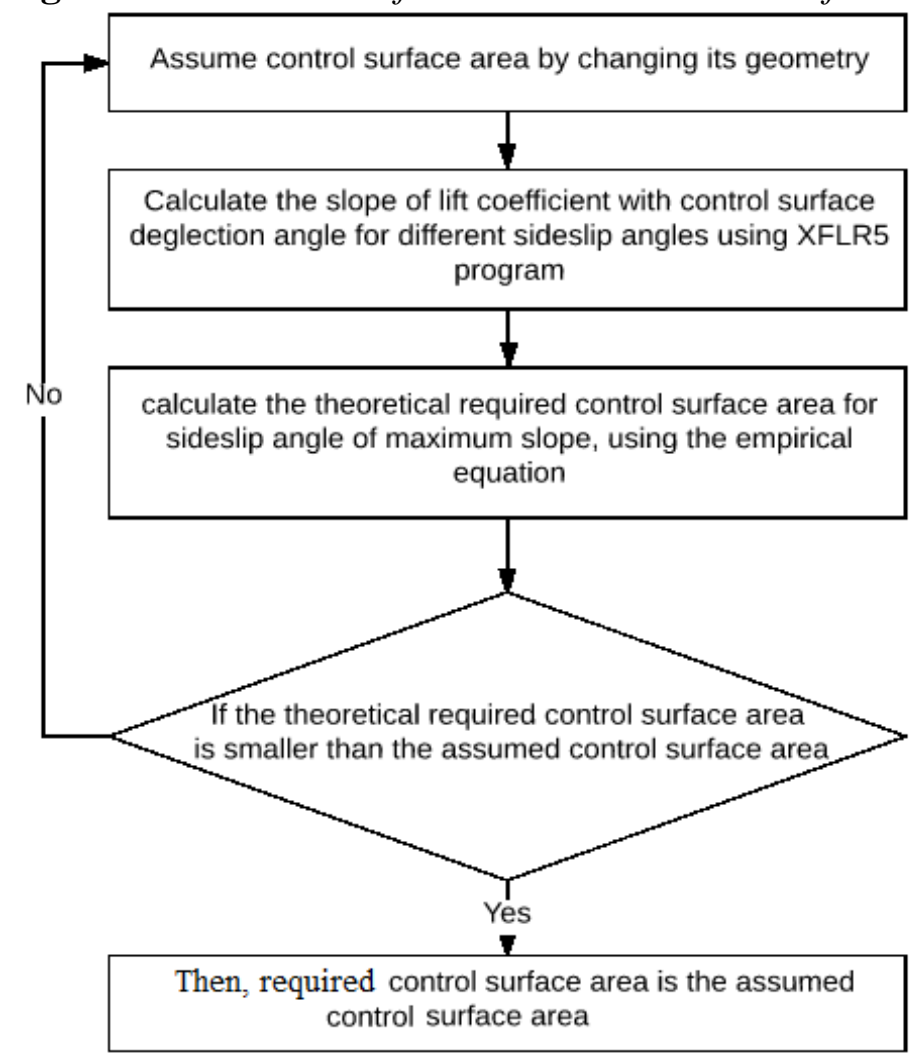


The final control surface size is defined by $50 \%$ tip chord, $40 \%$ root chord and $35 \%$ mid chord at distance $40 \%$ from tip.

\section{Winglet Geometry Design}

Mohamed (2016) gives the optimum winglet characteristics which achieve the maximum lift to drag ratio and are mentioned in Table 3.

Table 3. Values of Optimum Winglet Characters (Mohamed, 2016)

\begin{tabular}{lc}
\hline Character & Value \\
\hline $\mathbf{b}_{\mathbf{w l}}$ & 0.14 \\
$\mathbf{b}_{\mathbf{b w}}$ & \\
$\mathbf{C}_{\mathbf{w l r}}$ & 1.00 \\
\hline $\mathbf{C}_{\mathbf{b w t}}$ & 0.35 \\
$\boldsymbol{\lambda}_{\mathbf{w l}}$ & 60 degree \\
Cant angle & 8 degree \\
\hline Sitting angle
\end{tabular}

Where $\frac{b_{w l}}{b_{b w}}$ is the ratio of winglet span to basic wing semi-span, $\frac{b_{w l}}{c_{b w t}}$ is the ratio of winglet span to basic wing tip chord, $\frac{\mathrm{C}_{\mathrm{wlr}}}{\mathrm{C}_{\mathrm{bwt}}}$ is the ratio of winglet tip chord to basic wing tip chord and $\lambda_{\mathrm{wl}}$ is the tapered ratio of winglet.

The optimum values of $\frac{b_{w l}}{b_{b w}}$ and $\frac{c_{w l r}}{C_{b_{w t}}}$ are used but the planform wing taper ratio is taken to be as the winglet taper ratio which is 0.7 , due to the small values of $b_{w l}$ and $C_{w l r}$. The cant angle and sitting angle are set to be zero degree to be easy in manufacturing. The airfoil of winglet is chosen to be a symmetric airfoil NACA 0009.

\section{Aerodynamic Analysis}

2D and 3D analysis are performed by different methods and techniques to compare between them and verify the results.

2D Analysis

The analysis involves the airfoil's aerodynamic performance, which means obtaining lift and drag coefficients at a certain angle of attack (AOA) and pressure distribution over the airfoil surface. This analysis is accomplished by three different techniques: inviscid potential equation, turbulent Navier Stokes equation and XFoil analysis system. Each technique is accomplished by a different solver: homebuilt Matlab code, which can be shown in Hamada and Sultan (2016), 
commercial Fluent ANSYS program using Spalart Allmaras model and free XFLR5 program, respectively (ANSYS, 2015; Drela and Youngren, 2000).

The solution is obtained for a flow over the HS522 airfoil with AOA $=5^{\circ}$. Iso-non-dimensional velocity contours, carried by the homebuilt Matlab code and Fluent ANSYS program, are shown in Figures 10 and 11, respectively (ANSYS, 2015; Hamada and Sultan, 2016). Figure 12 shows the comparison of the pressure distribution over the airfoil's surface, obtained from the three different solvers. Also, Table 4 shows the values of lift and drag coefficients obtained from these techniques.

Figure 10. Contours of Iso-non-dimensional Velocity over HS522 Airfoil Surface with $A O A=5^{\circ}$, Obtained from Homebuilt Matlab Code

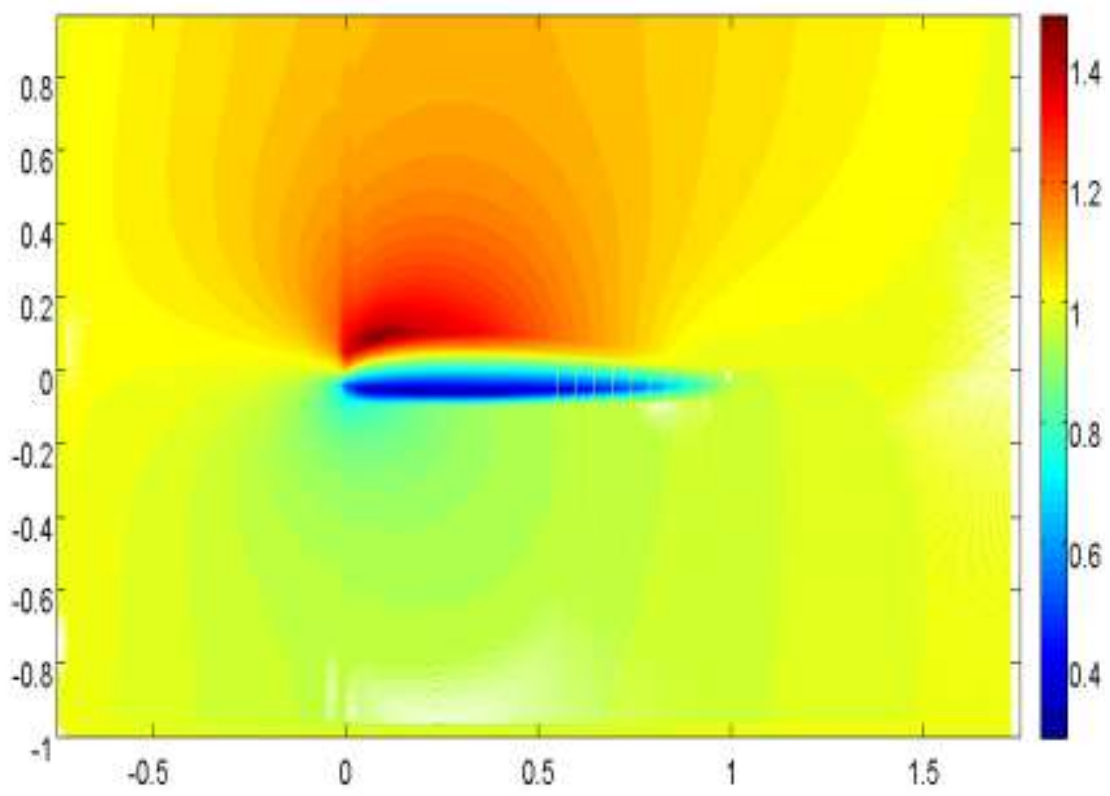

Figure 11. Contours of Iso-non-dimensional Velocity over HS522 Airfoil Surface with $A O A=5^{\circ}$, Obtained from Fluent ANSYS Program

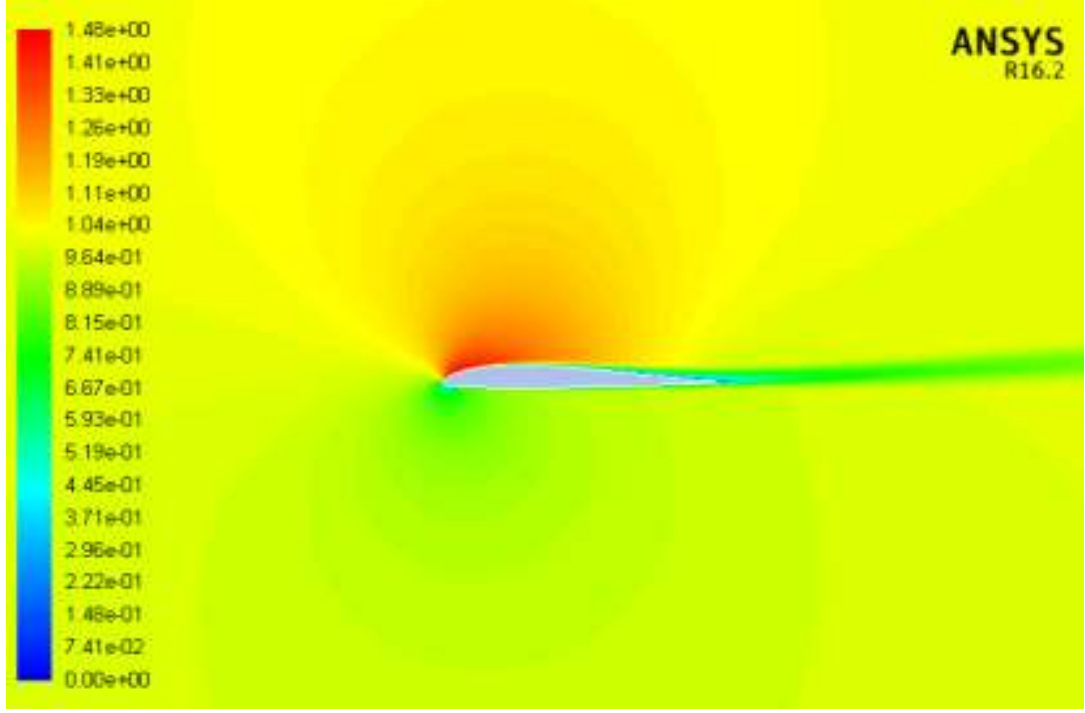


Figure 12. Comparison between Pressure Coefficient Distribution over HS522 Airfoil Surface with AOA $=5^{\circ}$, Obtained from Different $2 D$ Analysis Techniques

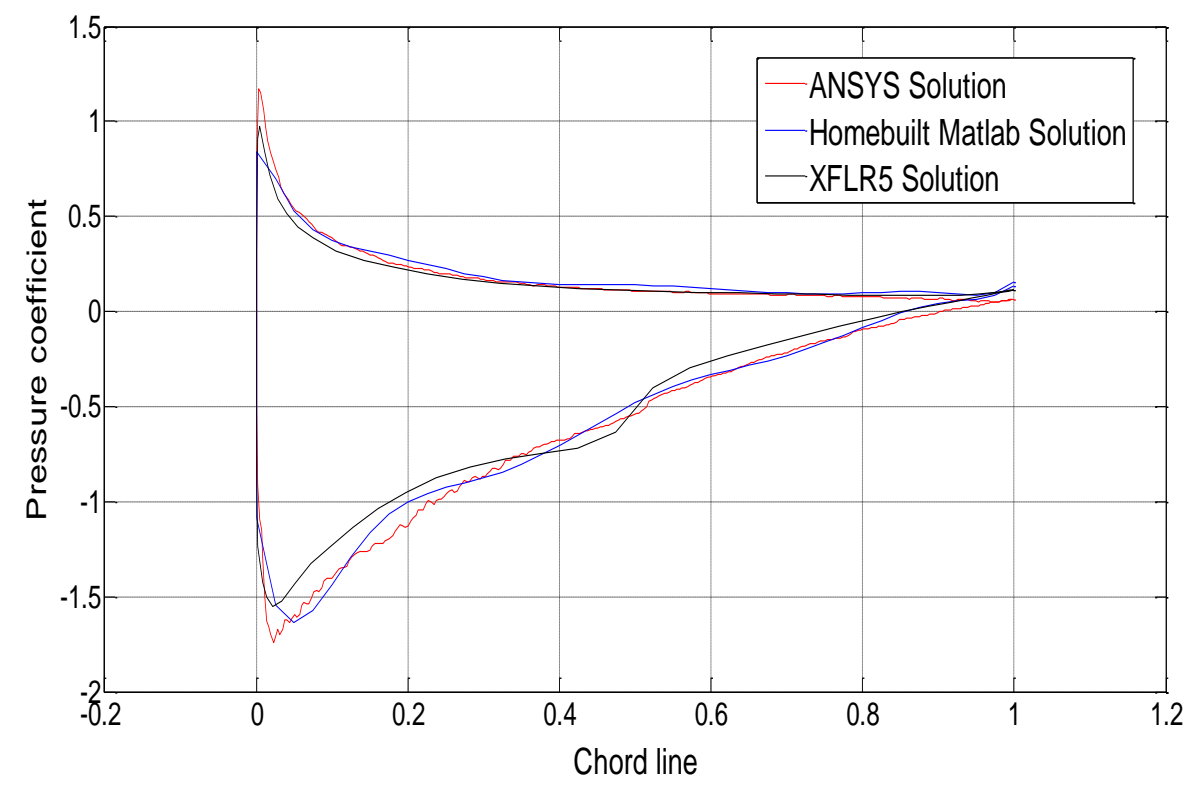

Table 4. Comparison between Values of Lift and Drag Coefficients of HS522 Airfoil Surface with AOA $=5^{\circ}$, Obtained from Different 2D Analysis Techniques

\begin{tabular}{lcc}
\hline \hline 2D Analysis Techniques & Lift Coefficient & Drag Coefficient \\
\hline Inviscid Potential Equation & 0.777 & -0.0085 \\
$\begin{array}{l}\text { Turbulent Navier Stokes } \\
\text { Equation }\end{array}$ & 0.7786 & 0.032465 \\
XFoil Analysis System & 0.7065 & 0.01666 \\
\hline \hline
\end{tabular}

Comparison between different methods shows a slight variation in lift coefficient. The drag coefficient resulting from the inviscid potential equation must be zero but the small negative value is due to numerical errors within the code itself. Comparing the drag coefficient in the remaining two cases, it can be seen that it is higher in case of the method of the turbulent Navier Stokes equation, as it takes into consideration the vortices resulting from the turbulent flow.

\section{D Analysis}

The analysis involves the aerodynamic performance of the flying wing which means obtaining variation of lift and pitching moment coefficients with angle of attack (AOA) and also obtaining the drag polar of the flying wing. This analysis is accomplished by a single technique: a 3D panel method, performed by two different solvers: the free XFLR5 program and a Matlab code (Drela and Youngren, 2010; Abbas and Abdelrahman, 2015). The effect of winglet on 
aerodynamic parameters is studied with the help of XFLR5 program (Drela and Youngren, 2010. The variation in results is shown in Figures 13 through 15.

Figure 13. Variation of Lift Coefficient of the Flying Wing with Angle of Attack

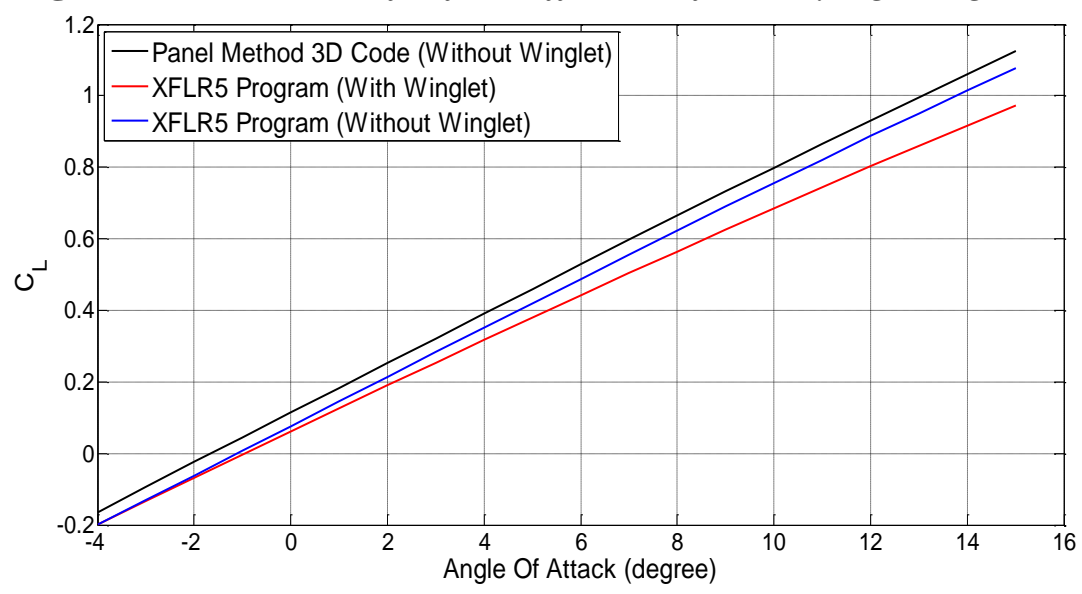

Figure 14. Drag Polar of the Flying Wing

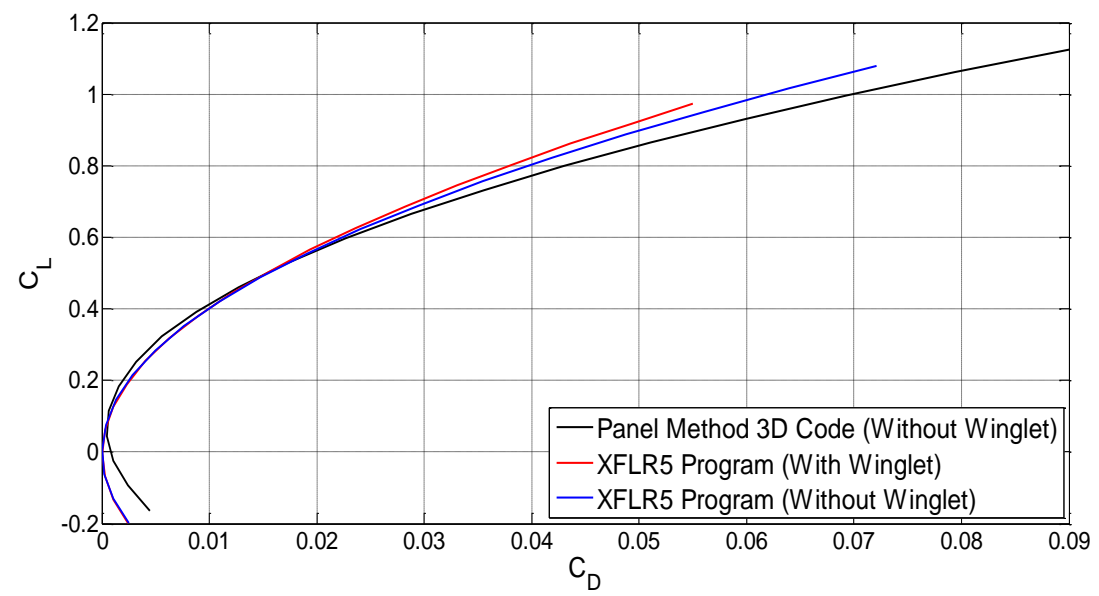

Figure 15. Variation of Moment Coefficient with Lift Coefficient of the Flying Wing

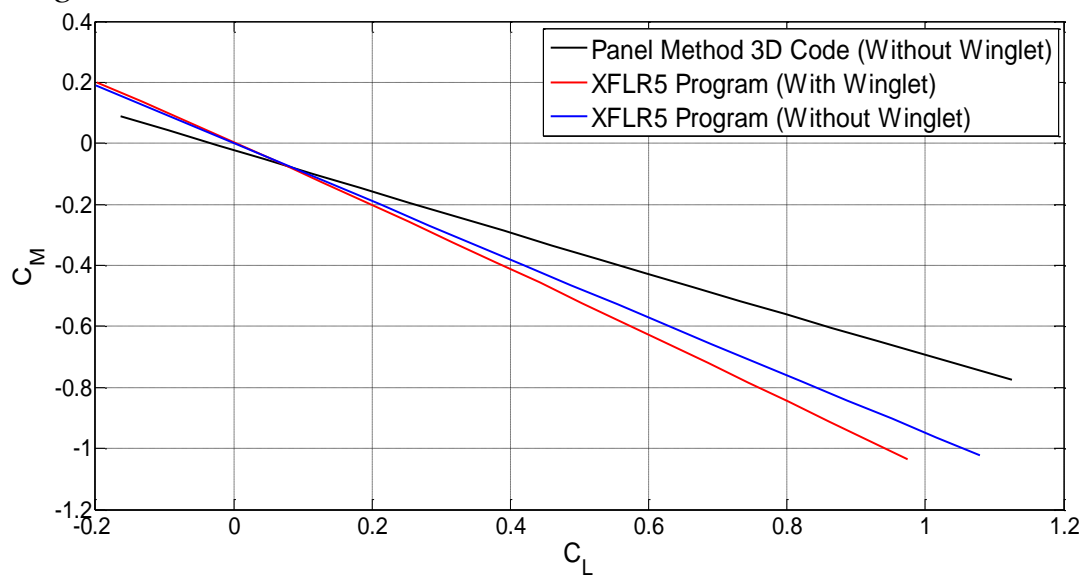


Winglets greatly reduce the drag as AOA increases. The high reduction in drag is due to the great reduction in induced drag, resulting from the cancelation of the tip vortices. Also, winglets negatively increase the slope of pitching moment coefficient curve. These obtained results are similar to those obtained in the research studies performed in NASA (Smith and Campbell, 1996).

\section{Wind Tunnel Testing}

A wind tunnel is a tool used in aerodynamic research to study the effects of air moving past solid objects. The test object, often called a wind tunnel model, is instrumented with suitable sensors, load cells, to measure aerodynamic forces.

A fixation system for the model is designed where the load cells are fixed to the winglets of the models and from the other sides, they are fixed to carbon fiber rods, supported on the wind tunnel's walls by a bearing to enable the rotation of the model. An arm and a plate with holes, fixed outside the wind tunnel, are used to fix the model at various angles of attack. A SolidWorks photo of the fixation system of the model, used in the wind tunnel is shown in Figure 16 (Dassault Systemes, 1995-2012).

Figure 16. SolidWorks Photo of the Fixation System of the Model, Used in the Wind Tunnel (Dassault Systemes, 1995-2012)

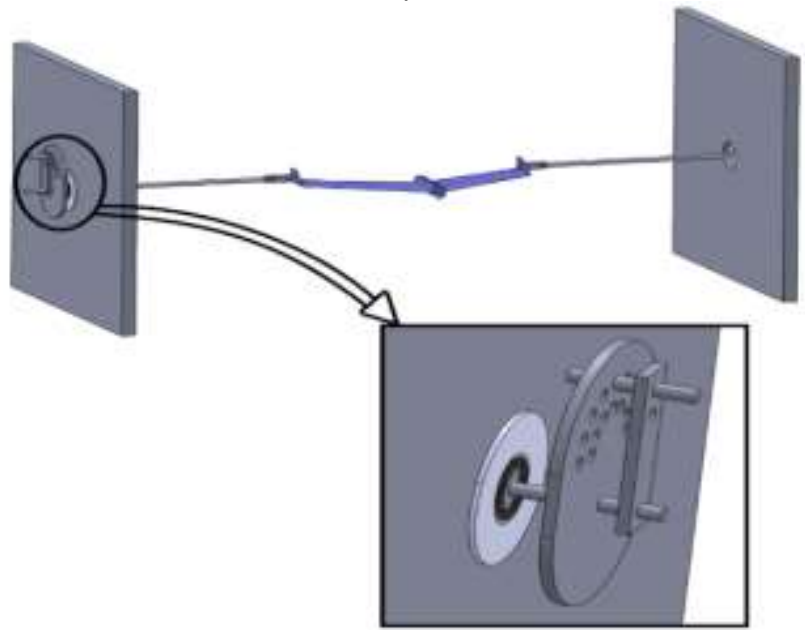

Finally, the experimental results, obtained from the wind tunnel, are compared with the theoretical results obtained from XFLR5 program (Drela and Youngren, 2000). Curve fitting is used due to the existence of small vibrations during testing. Variations of lift and drag coefficients with angle of attack are shown in Figures 17 and 18 , respectively. 
Figure 17. Variation of Lift Coefficient with Angle of Attack for Flying Wing

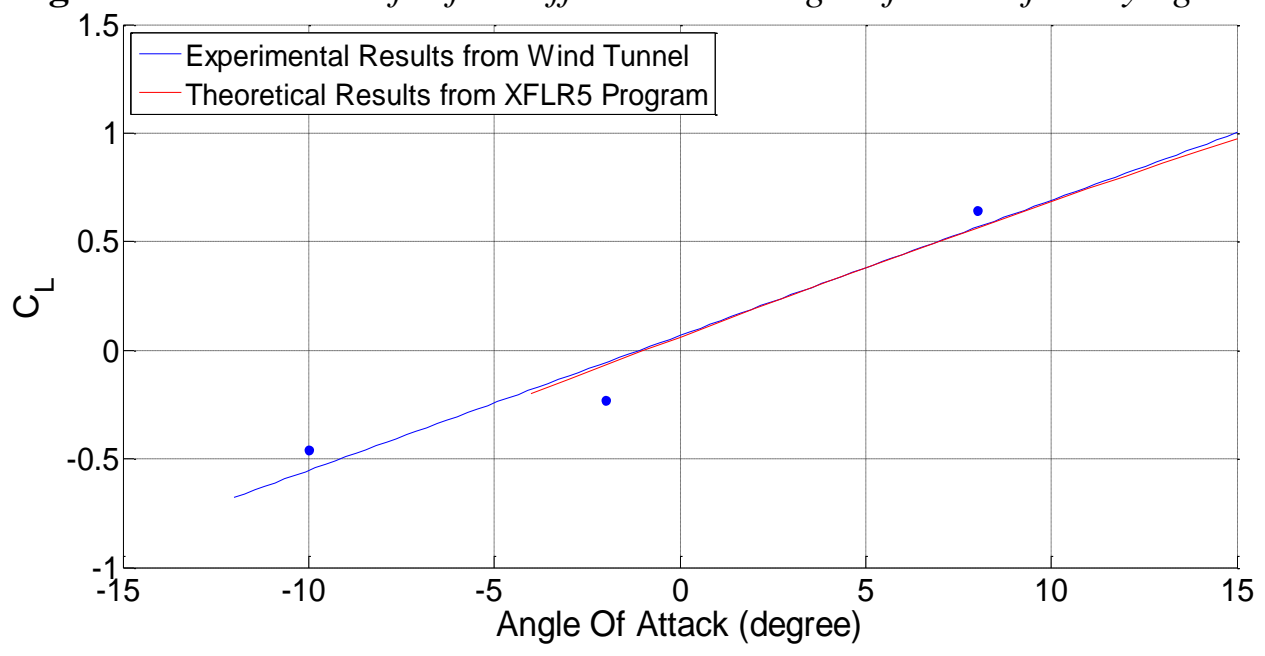

Figure 18. Variation of Drag Coefficient with Angle of Attack for Flying Wing

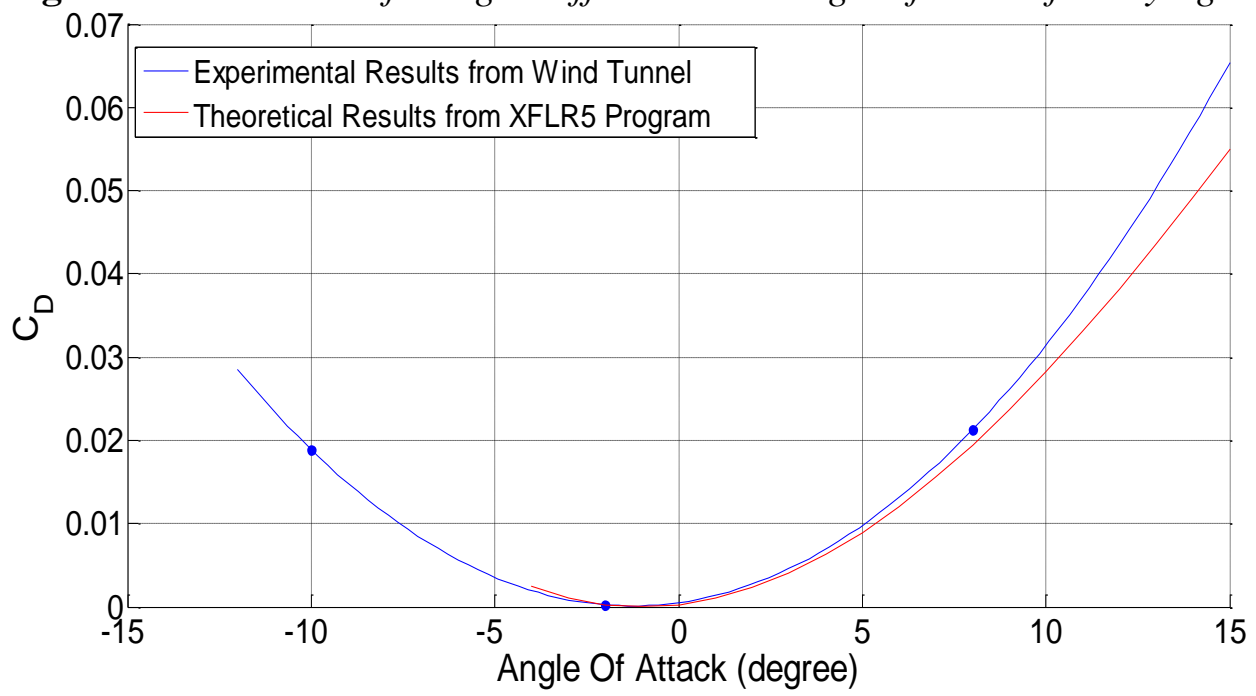

\section{Detailed Design}

\section{Electric and Electronic Components}

It is decided to use an electric brushless motor for the propulsion system of the flying wing. Then, the propulsion system components are brushless motor, engine accessories (engine mount, propeller adaptor, bullet connectors ..., etc.), lithium polymer (LIPO) battery, electronic speed controller (ESC), puller propeller, torque servo motors and battery charger. The chosen components are summarized in Table 5. 
Table 5. Components Used in the Flying Wing

\begin{tabular}{lcc}
\hline Component & \multicolumn{1}{c}{ Specifications } \\
\hline Electric Brushless Motor & $\mathrm{Kv}$ & $1100 \mathrm{Kv}$ \\
& Weight & $38 \mathrm{gm}$. \\
& Power & $102 \mathrm{Watts}$ \\
& Thrust & $520 \mathrm{gm}$. \\
Electronic Speed & Constant Current & $30 \mathrm{Amp}$. \\
Controller & Weight & $27 \mathrm{gm}$. \\
Battery & Capacity & $3000 \mathrm{~mA} . \mathrm{hr}$. \\
& Weight & $195 \mathrm{gm}$. \\
Propeller & Pitch & $4.5 \mathrm{inch}$ \\
& Diameter & $10 \mathrm{inch}$ \\
Torque Servo Motor & Torque & $1.3 \mathrm{~kg} . \mathrm{cm}$ \\
& Weight & $9 \mathrm{gm}$. \\
\hline \hline
\end{tabular}

\section{Material Selection}

Foam has revolutionized RC model airplane building. It is inexpensive to buy, costing a lot less than an equivalent block of balsa. It is of a consistently high quality and widely available. It can be easily cut and scrabbled. The stiffness of foam, when looked at by weight, is comparable to balsa/black ash. Foam does not have balsa/black ash strength, and are generally lower in density than wood.

Dow BlueCor foam is chosen to be the main material of the flying wing body (RCfoam Website, 2017). The flying wing body is stiffened by using a carbon rod along each wing and supported in the fuselage by a small thin black ash plate in the middle.

\section{Computer Aided Design}

The flying wing is drawn using SolidWorks to improve the quality of the design, create the database for manufacturing and produce a very accurate design and provide a visualization of the final product (Dassault Systemes, 1995-2012).

Figure 19. SolidWorks Model of the Flying Wing

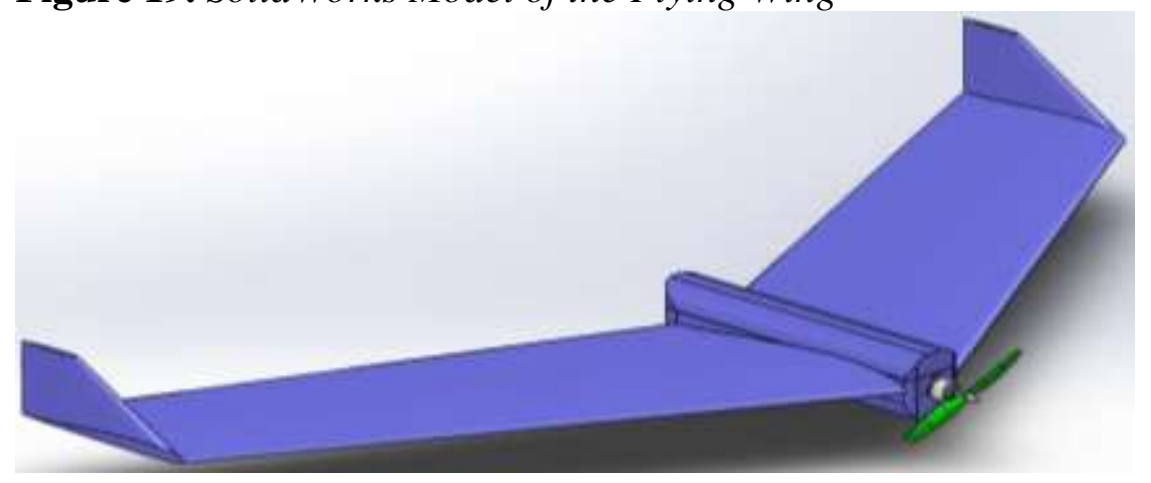


Electronic components are implemented in a way that results in a stable center of gravity position for the flying wing, which is checked by XFLR5 program (Drela and Youngren, 2000). Figure 19 shows the CAD model of the flying wing. This CAD model is used to predict the position of the center of gravity. The C.G. position lies at about $250 \mathrm{~mm}$ behind the nose of the fuselage.

\section{Stability}

Static and dynamic stability analyses are performed using the XFLR5 Program (Drela and Youngren, 2000). Both cases, with and without the winglet, are analyzed to study the effect of winglet on the stability of the flying wing. For each case, two flight conditions, steady level flight and steady level turn, are considered. It is observed that changing the deflection angle of the control surfaces, changes the stability derivatives and the control derivatives.

In the case of the flying wing without winglets in steady level flight, stability analysis is possible for the range of elevons deflections of [-7, -3]. However, the long period mode and spiral mode are found to be unstable, for most of the range of the deflection angles of the control surfaces. Moreover, AOAs required to trim the flying wing are found to be high which is unfavorable.

In the case of the flying wing with winglets in steady level flight, stability analysis is possible for the range of elevons deflections of $[-12,-5.5]$ which is wider than that without winglets case. In addition, the long period mode is found to be stable but unfortunately, spiral mode is found to be unstable for most of the range of the deflection angles of the control surfaces.

In the case of the flying wing without winglets in steady level turn, the spiral mode is found to be unstable, for most of the range of the deflection angles of the control surfaces. Moreover, velocities required to turn the flying wing are found to be high which is unachievable by the selected motor. However, for the case of the flying wing with winglets in a steady level turn, the spiral mode is found to be very close to zero (critically stable), for most of the range of the deflection angles of the control surfaces.

Through the previous results, it can be seen that the winglets have a high impact on stability. Winglets improve the stability of the long period mode in steady level flight condition and that of the spiral mode in steady level turn.

\section{Simulation of Flying Wing Motion}

There exist two types of simulation problems for the flying wing; the direct and the inverse simulation problems. Matlab codes are built, to solve both the direct and the inverse simulation problems with the generalized technique (Abdelrahman and Al-Bahi, 1994). 


\section{Direct Simulation}

The direct simulation problem is a simple one where the dynamic and kinematic equations of motion are directly used to simulate the flying wing behaviour. The inputs of the direct simulation problem are control surface deflection and thrust while the output is the trajectory. There are many combinations of these two inputs. However, the chosen combination is that fixed value of the control surface deflection angle, which is 0.58 degree, and variable thrust with time, as shown in Figure 20.

As it is seen in Figure 21, the resulting trajectory yields a small increase in altitude over a large horizontal distance. This is due to the absence of a negative elevator deflection so no nose up motion occurs. It should also be noted that the trajectory does not return to the original altitude after the thrust decreases which is because the resulting decrease in velocity, as shown in Figure 22, is enough to trim the flying wing at the higher altitude.

Figure 20. Variation of Thrust with Time

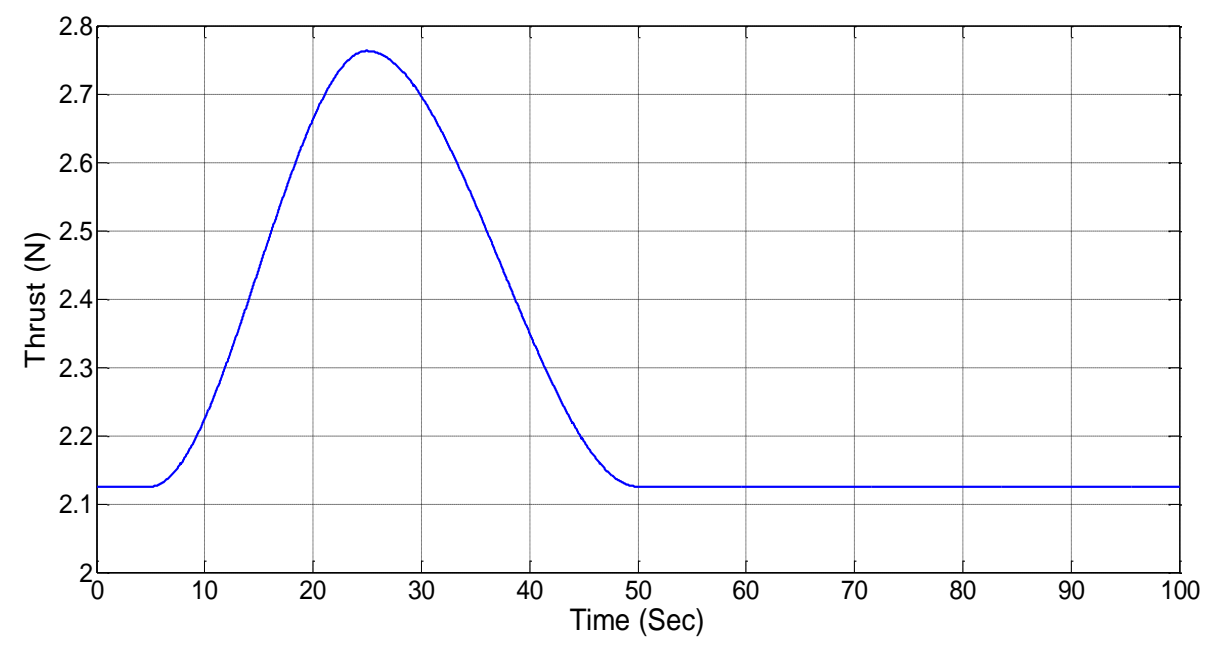

Figure 21. Trajectory of the Flying Wing

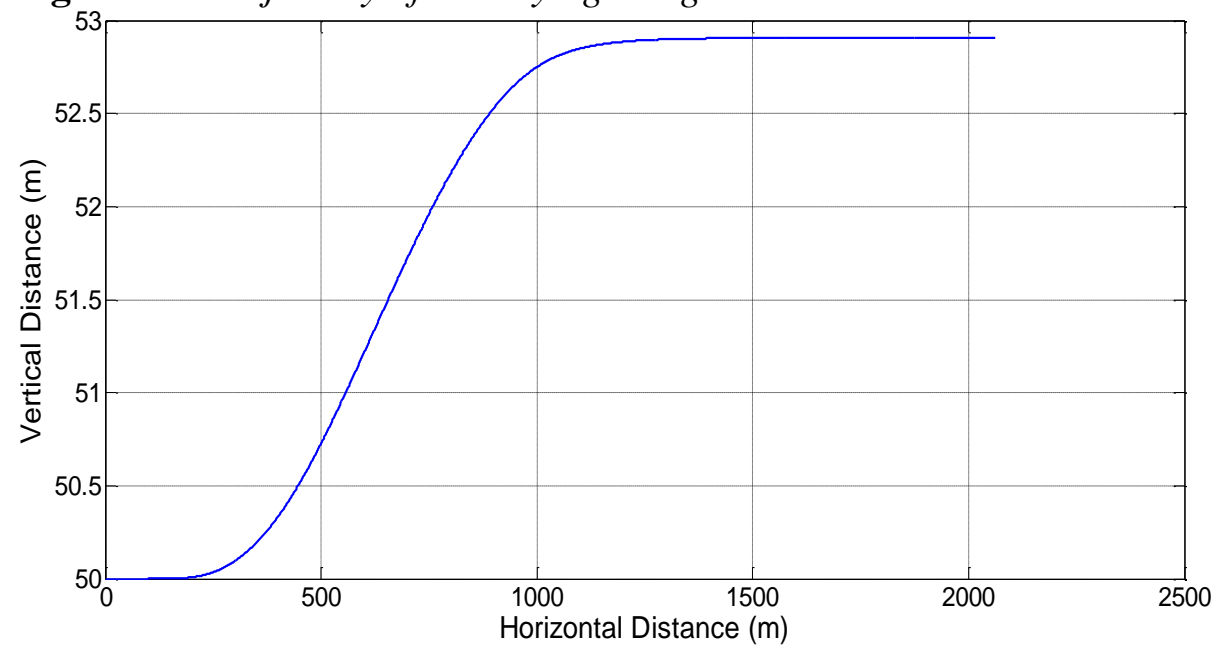


Figure 22. Variation of Velocity with Time

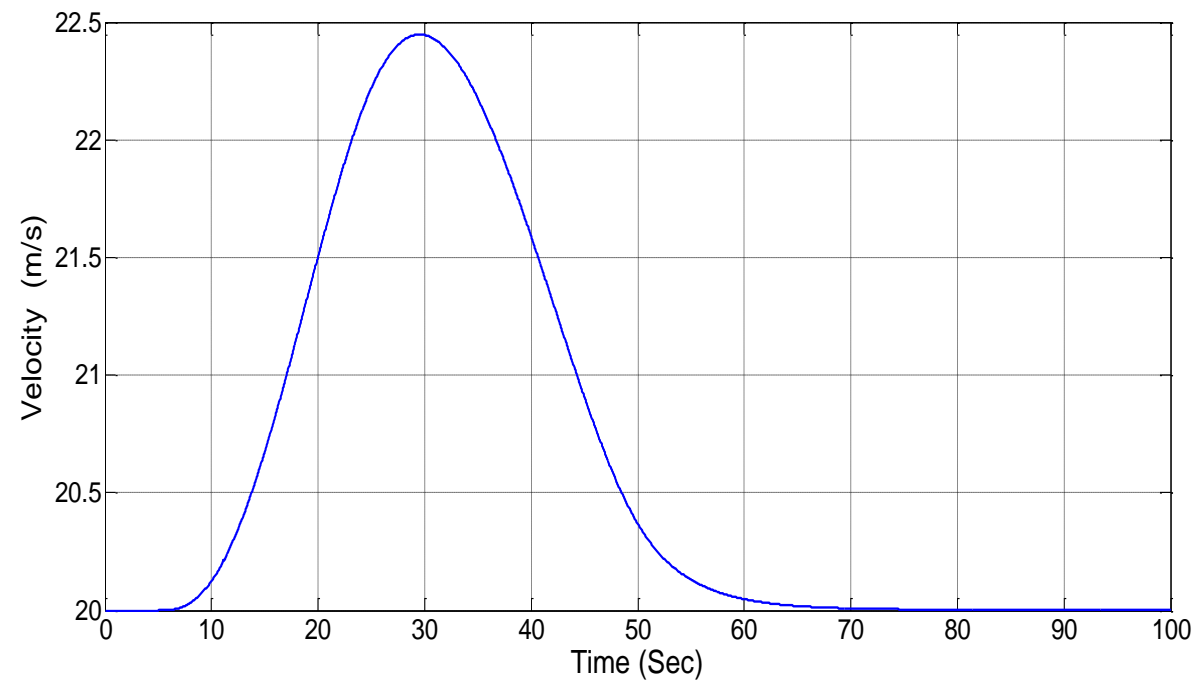

\section{Inverse Simulation}

The inverse simulation problem is more complicated than the direct one. The equations in this case are not directly solved and the problem requires special procedure to reach the solution (Abdelrahman and Al-Bahi, 1994).

The input to the inverse problem is the required trajectory and the outputs are the control surface deflection and the thrust required to achieve it. The chosen trajectory is taken a simple one that resembles the actual climb path as shown in Figure 23. Variations of AOA, pitch angle, flight angle and velocity with time are obtained during the solution and shown in Figure 24. The outputs are shown in Figures 25 and 26.

Figure 23. The Chosen Input Trajectory

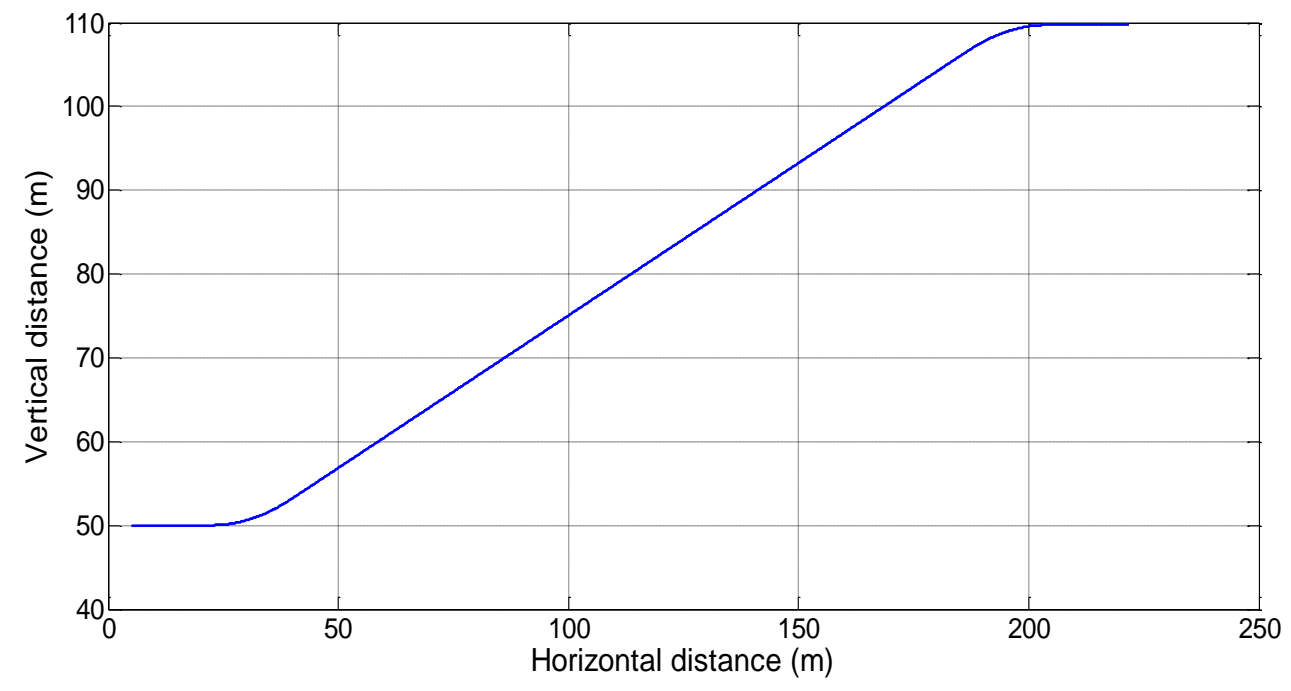


Figure 24. Variations of AOA, Pitch Angle, Flight Angle and Velocity with Time
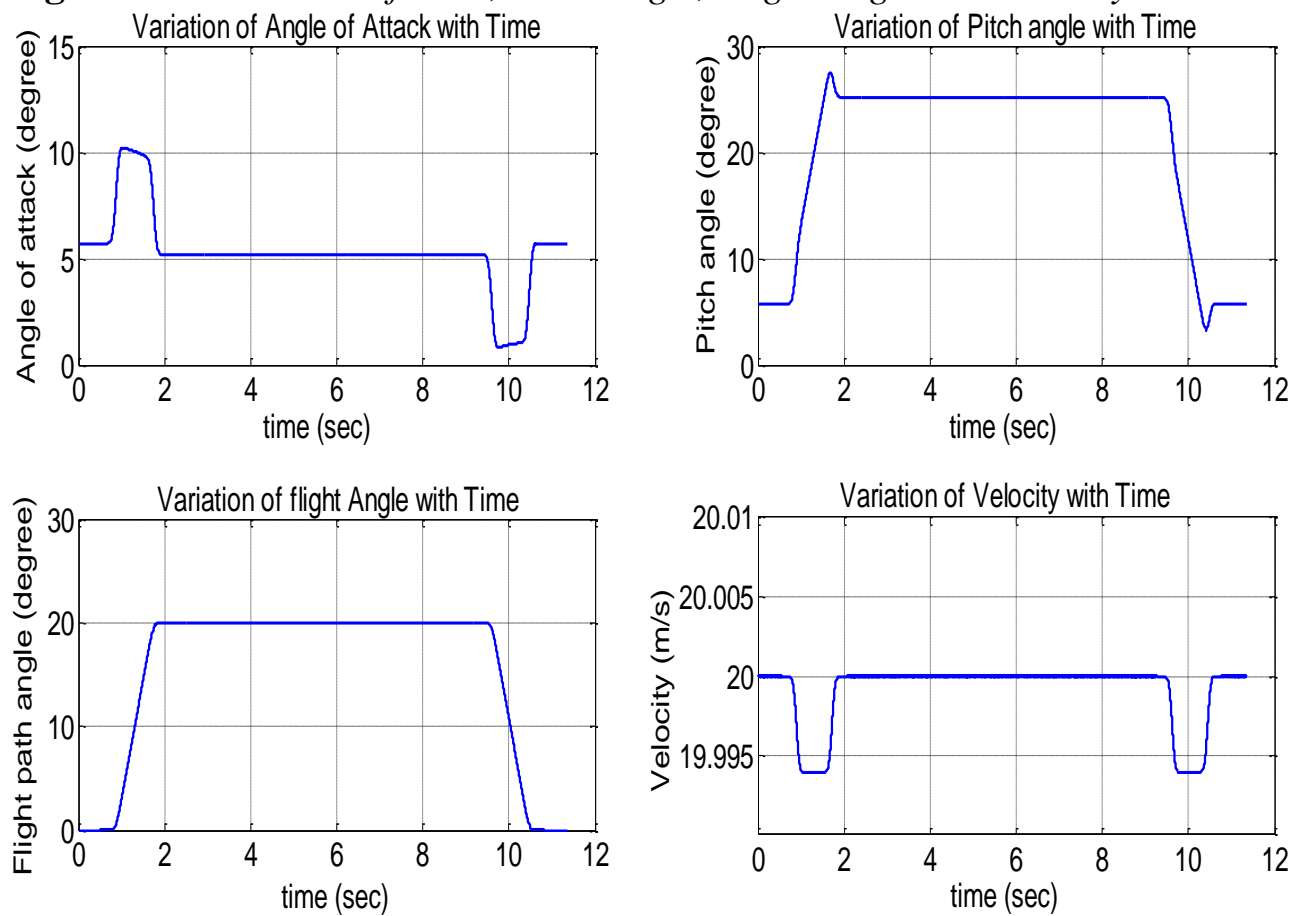

Figure 25. Variation of Elevator Deflection Angle with Time

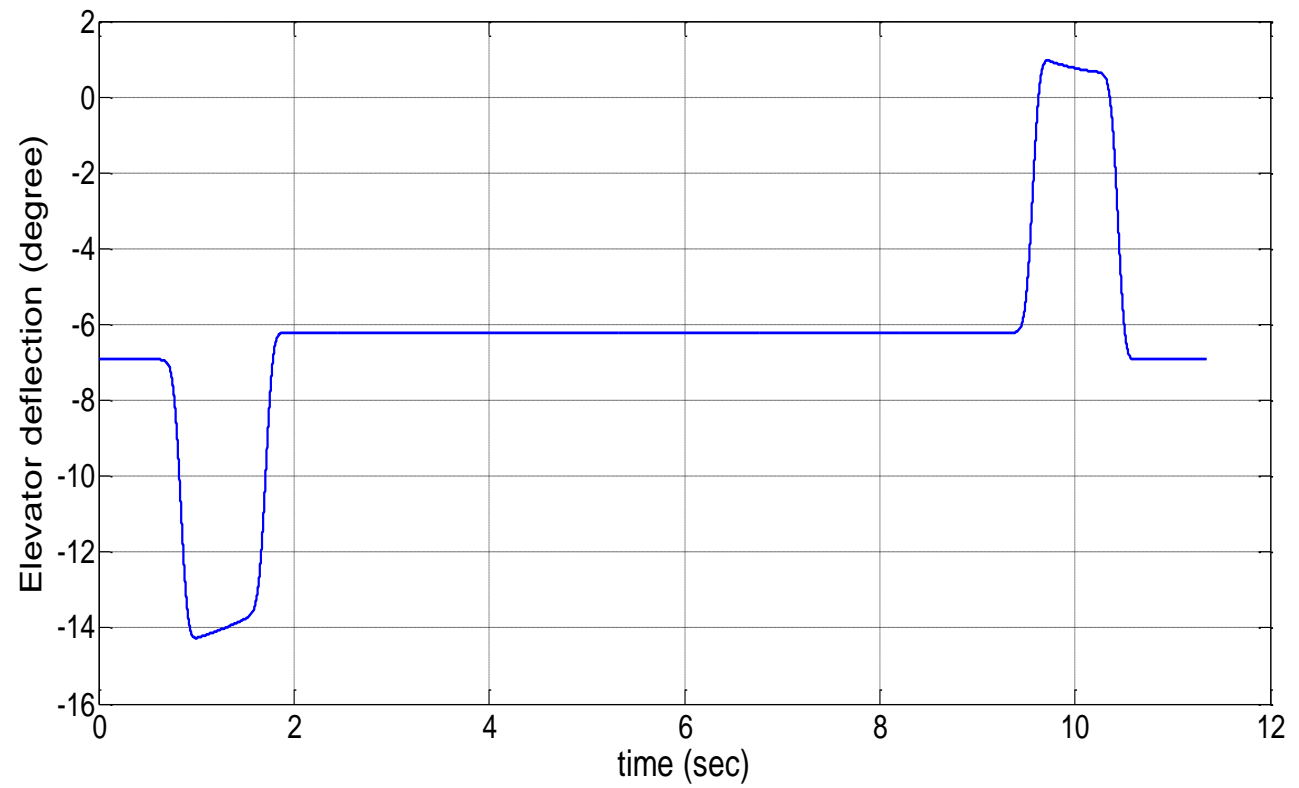


Figure 26. Variation of Thrust with Time

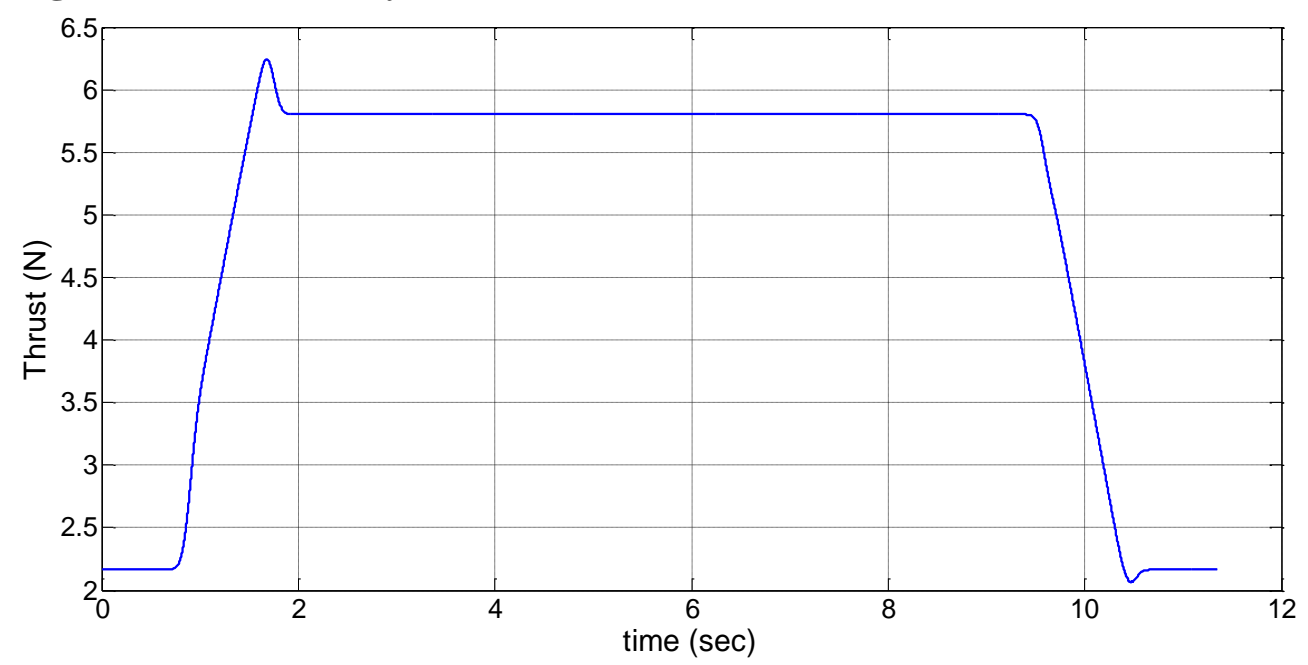

The output shows that the elevator deflection follows the change in path as expected. The control surface takes a rough deflection angle during the sudden change in the trajectory (right before and right after the steady climb). Then it is almost constant during the steady climb but yielding a smaller deflection than that of the steady-level flight. For the second output, the thrust, it can be seen that it increases whenever needed to change the altitude and decreases otherwise. It is also worth mentioning that the needed thrust and control surface deflection can both be achieved by the chosen electronic components.

\section{Performance Analysis}

An analysis of the performance of the flying wing is carried for different flight conditions, with the aid of traditional literature: "Aircraft Performance and Design" (Anderson (1998). The analysis is carried by a homebuilt Mathematica code, which can be seen in the B.Sc. graduation project, accomplished in Cairo University (Hamada and Sultan, 2016).

The drag polar, equation (2), is the relation between the lift and drag on the flying wing. It can be represented as:

$$
\mathrm{C}_{\mathrm{D}}=\mathrm{C}_{\mathrm{D}_{0}}+\mathrm{KC}_{\mathrm{L}}^{2}
$$

Where, $C_{D}$ is the total drag coefficient, $C_{D_{0}}$ is the zero-lift drag coefficient, $C_{L}$ is the lift coefficient and $K$ is a proportionality constant which equals $1 / \pi e_{0} A R$ ( $\mathrm{e}_{0}$ is the Oswald efficiency factor 0.75-0.9).

Following the common procedure of the calculation of the drag polar, the final result is: $\mathrm{C}_{\mathrm{D}_{0}}=0.0195, \mathrm{~K}=0.0734$. 


\section{Steady Level Flight}

Figure 27. Variation of Power Required and Power Available with Velocities

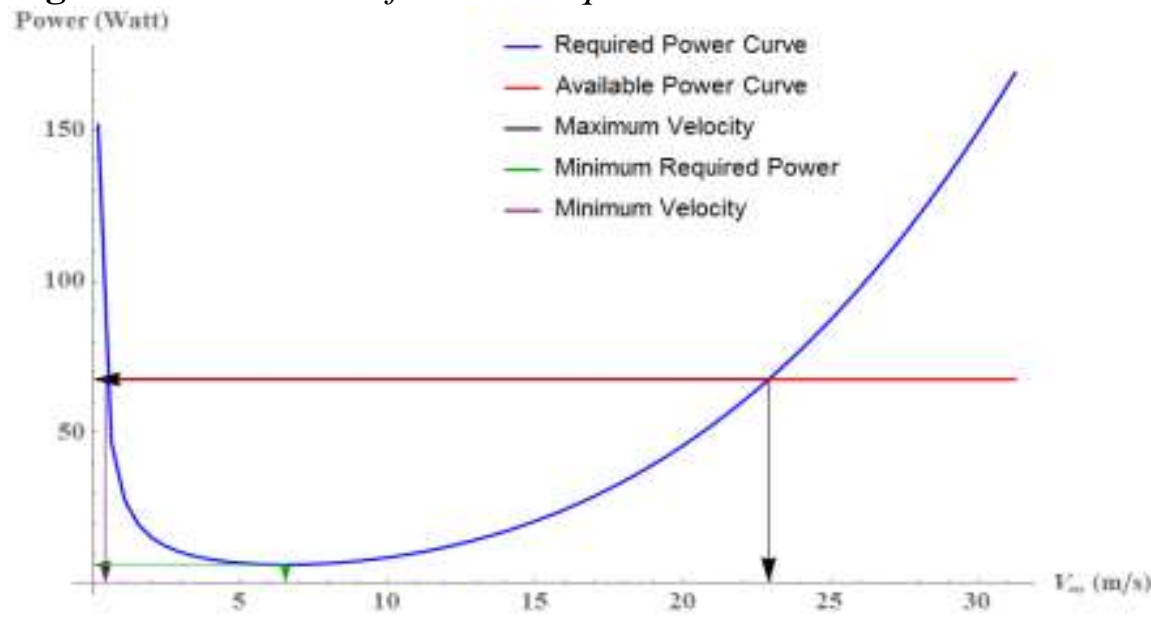

During the steady level flight, two approaches can be taken to reach the values of the maximum and minimum velocities, either considering the thrust or power. Power is usually divided into two types, one required to overcome the drag acting on the flying wing, the other is the power that can be provided by the propulsion system. These are called the power required and power available, respectively. The power approach will be shown graphically in Figure 27.

The resulting power curves intersect at two points. The one on the right represents the maximum velocity that can be reached. The other point of intersection should be compared with the stall velocity, and if found smaller, then it is considered just a numerical solution with no physical significance and the stall speed then represents the actual minimum speed of the flying wing. Table 6 shows the maximum and minimum velocities for the flying wing.

Table 6. Summary of the Critical Velocities of the Flying Wing

\begin{tabular}{lc}
\hline \hline Velocity & Value \\
\hline Maximum Velocity & $22.907 \mathrm{~m} / \mathrm{s}$ \\
Minimum Velocity & $6.695 \mathrm{~m} / \mathrm{s}$ \\
\hline \hline
\end{tabular}




\section{Steady Climb}

Figure 28. Climbing Hodograph for the Flying Wing (Vertical Velocity vs. Horizontal Velocity)

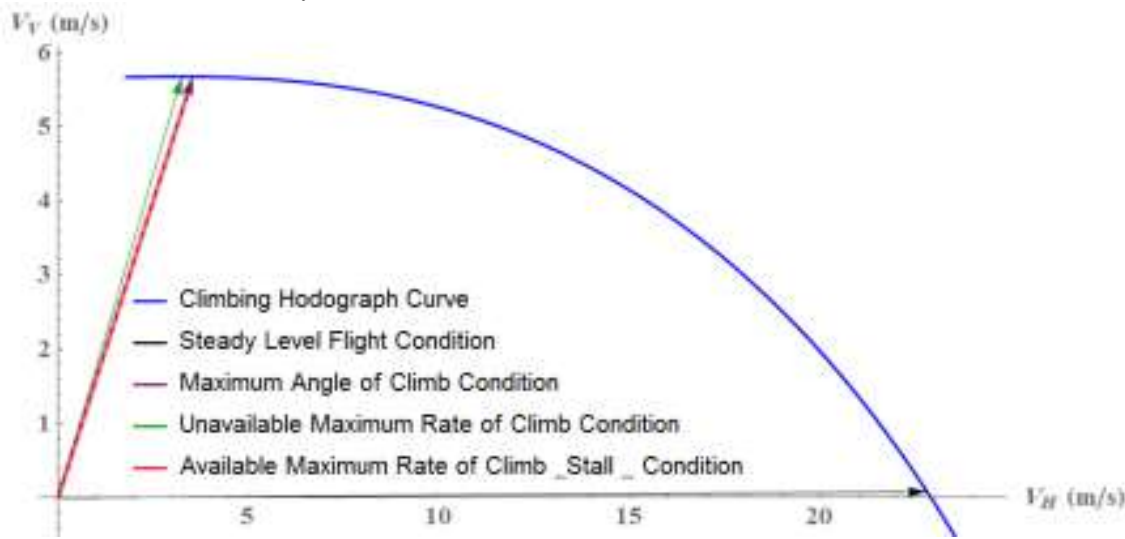

The flying wing needs to go through a steady climb to reach the required cruising altitude. The two main parameters to consider through the climb are the maximum climb angle and the maximum rate of climb.

The final values are found to be 58 degrees and $5.7 \mathrm{~m} / \mathrm{s}$ for the climb angle and the rate of climb, respectively. It is also important to mention that the velocities corresponding to both parameters are compared to stall speed, and if found smaller, they are calculated at the stall speed of the flying wing. The hodograph plane, shown in Figure 28, is used to represent these results graphically.

\section{Gliding}

A similar approach to that of the steady climb is followed in the gliding performance. However, the main parameters here are the minimum glide angle (maximum range) and minimum rate of descent which yield the values of 3.4 degree and $0.5 \mathrm{~m} / \mathrm{s}$, respectively. The gliding hodograph is shown in Figure 29.

Figure 29. Gliding Hodograph for the Flying Wing (Vertical Velocity vs. Horizontal Velocity)

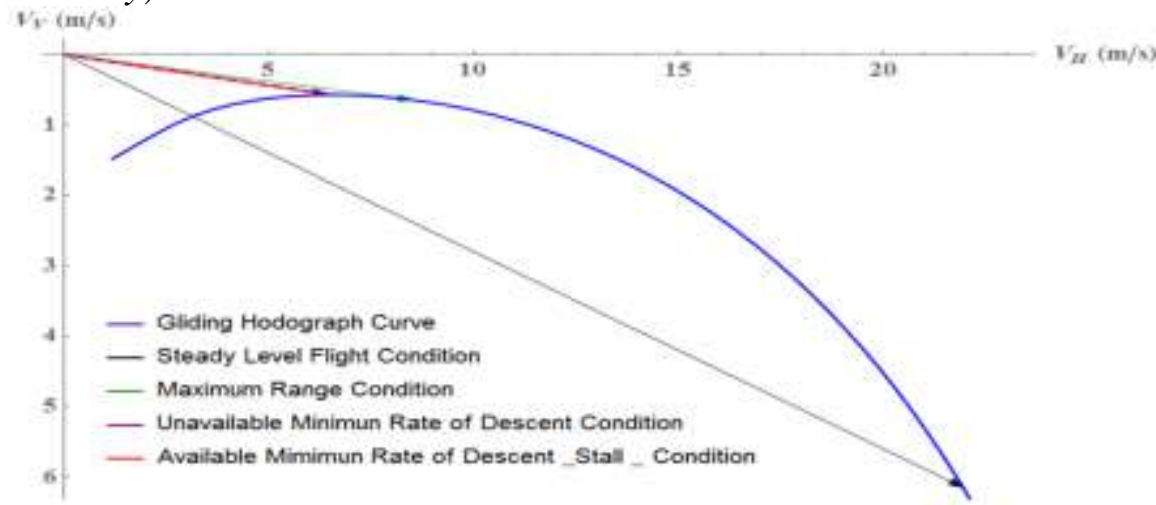




\section{Range and Endurance}

For conventional airplanes, the calculation of range and endurance heavily depends on the fuel consumption and the change of the mass of the airplane with time. However, in case of an electrical power plant, a different approach is needed. This is provided by a research paper that discusses the range and endurance of electric planes (Traub, 2011). Equations (3) and (4) show the governing equations of the endurance and the range of an airplane as functions of the battery parameters.

$$
\begin{gathered}
E=\left(R_{t}\right)^{1-n}\left(\frac{\eta_{\text {tot }} v c}{\left(\frac{1}{2} \rho v^{3} s C_{D_{0}}+\left(2 W^{2} K / \rho V s\right)\right.}\right)^{n} \\
R=E \times V
\end{gathered}
$$

Where, $\mathrm{V}$ is the airplane velocity, $\mathrm{S}$ is the reference area, $\mathrm{E}$ is the endurance (in hours), $\mathrm{R}$ is the range, $\mathrm{R}_{\mathrm{t}}$ is the battery hour rating (in hours), $\mathrm{n}$ is a discharge parameter dependent on the battery type and temperature, $\eta_{\text {tot }}$ is the effect of propeller, motor driver and motor, $\mathrm{v}$ is the volt of the battery used and $\mathrm{C}$ is its capacity. For small rechargeable battery packs, $R_{t}=1 \mathrm{~h}$, considering an ideal battery makes $\mathrm{n}=1$.

Figures 30 and 31 show the variation of range and endurance with flight velocities.

Figure 30. Variation of Endurance with Velocity

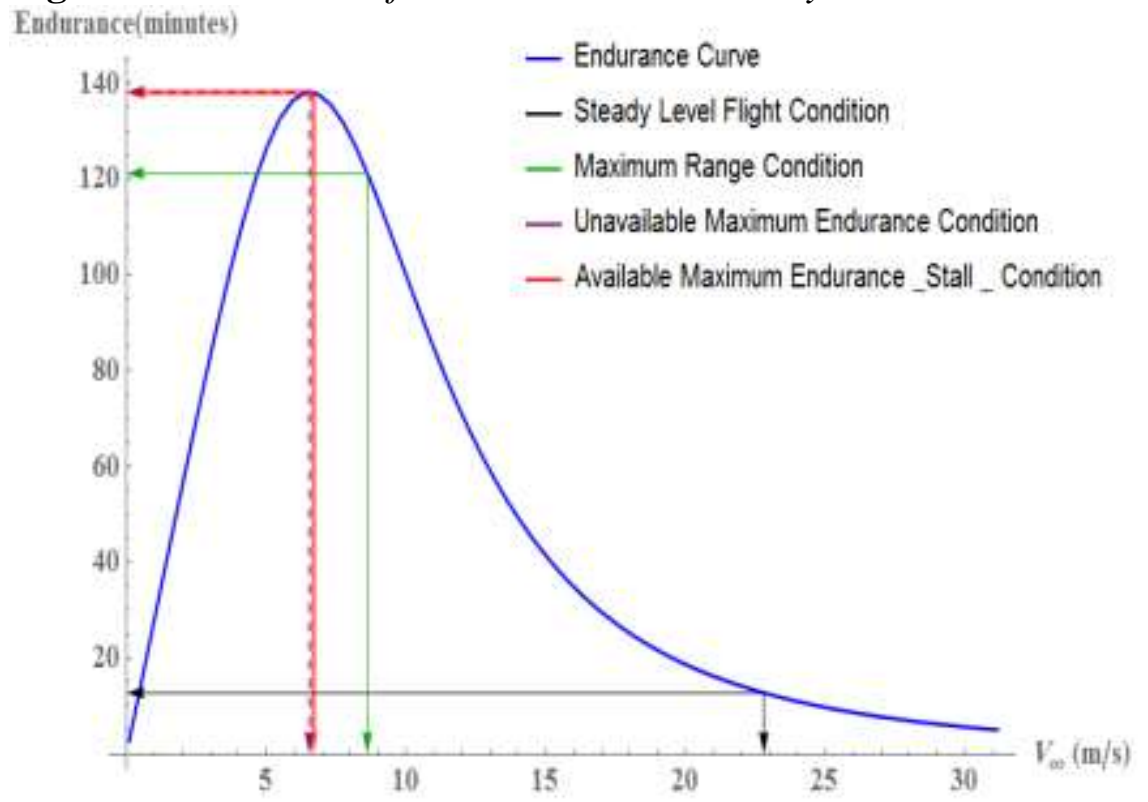


Figure 31. Variation of Range with Velocity

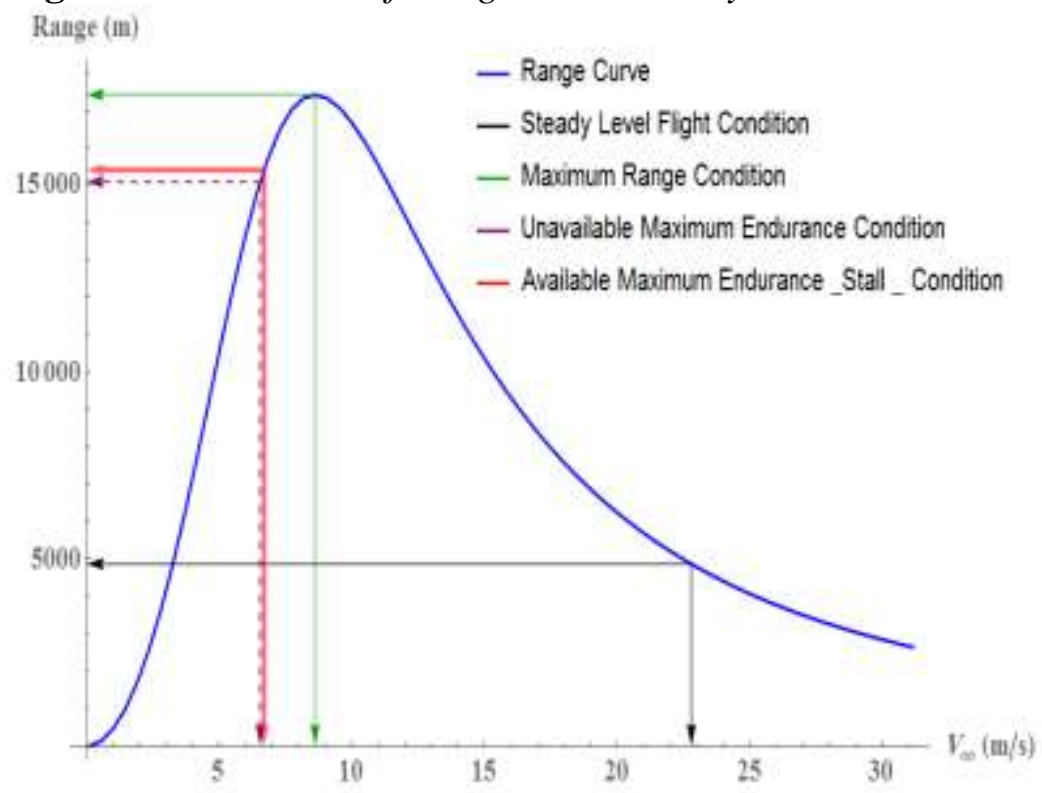

Figure 32. Variation of Maximum Load Factor with Velocity

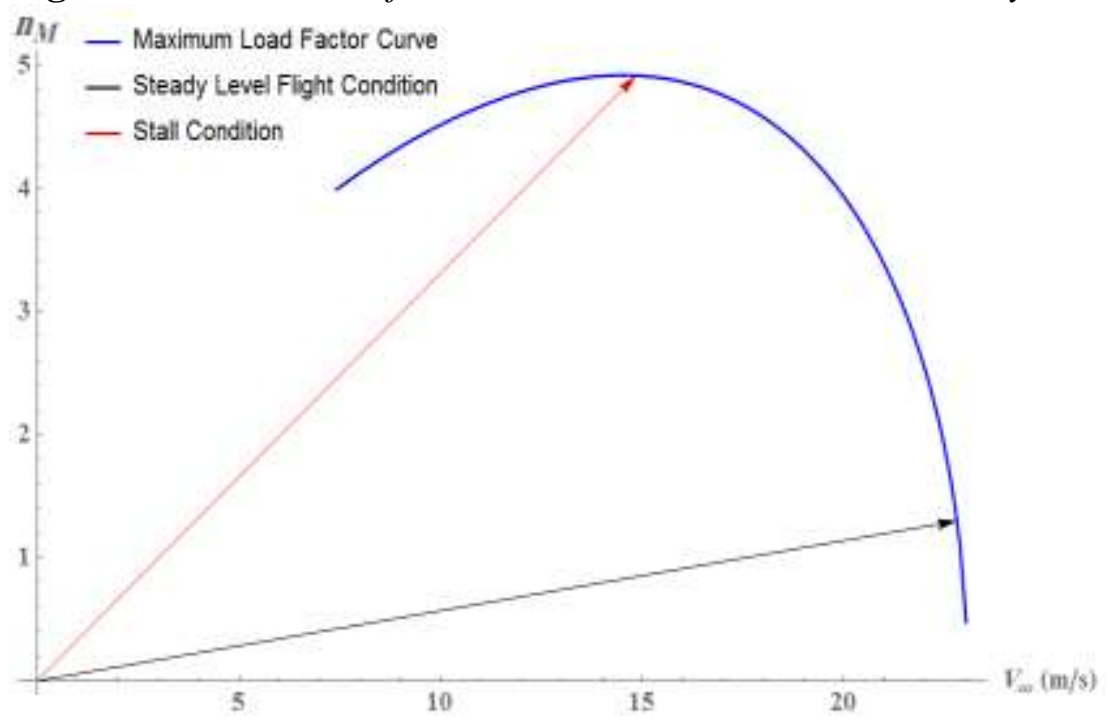

\section{Study Level Turn}

One of the important simple maneuvers is the level turn. Performing a level turn means flying in a curved horizontal path parallel to the ground. There are three main parameters that define this maneuver: the minimum turn radius $(R)$, the maximum turn rate $(\omega)$ and the maximum load factor $(n)$. They were all found to occur at the minimum velocity which is the stall velocity and their values are as follows:

$$
\mathrm{n}=4.92, \quad \mathrm{R}=4.666 \mathrm{~m}, \quad \omega=3.183 \text { degree } / \mathrm{sec}
$$


Figures 32 through 34 show the variation of these parameters with velocity.

Figure 33. Variation of Level Turn Radius with Velocity

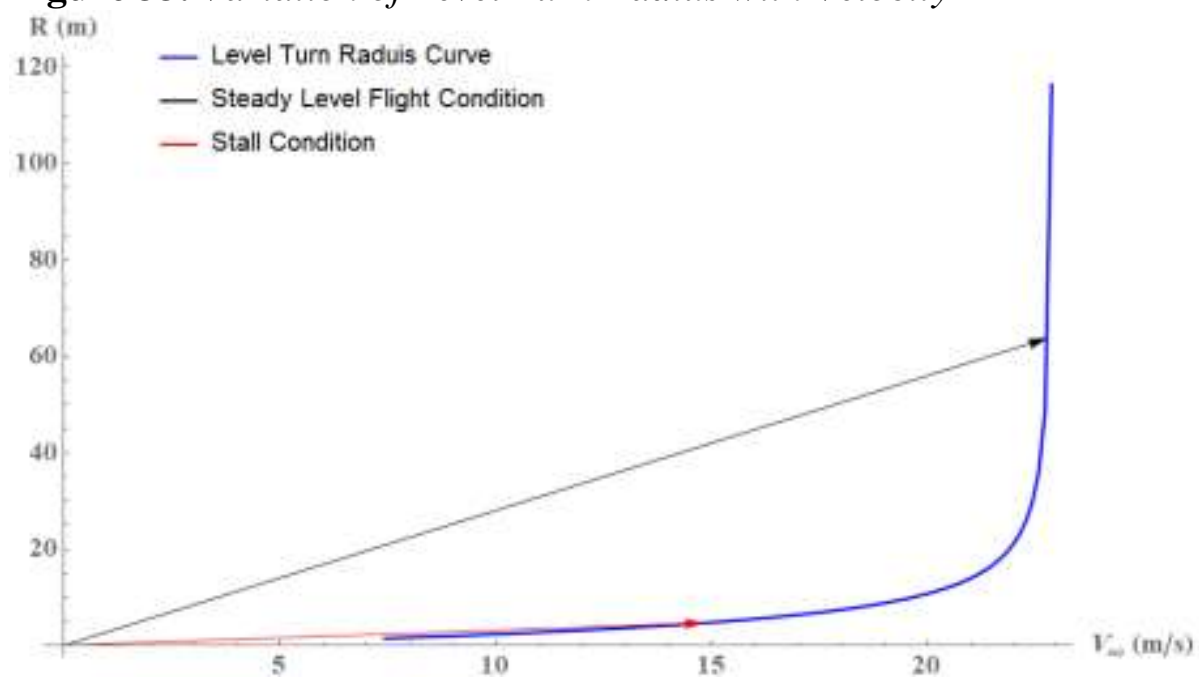

Figure 34. Variation of Level Turn Rate with Velocity

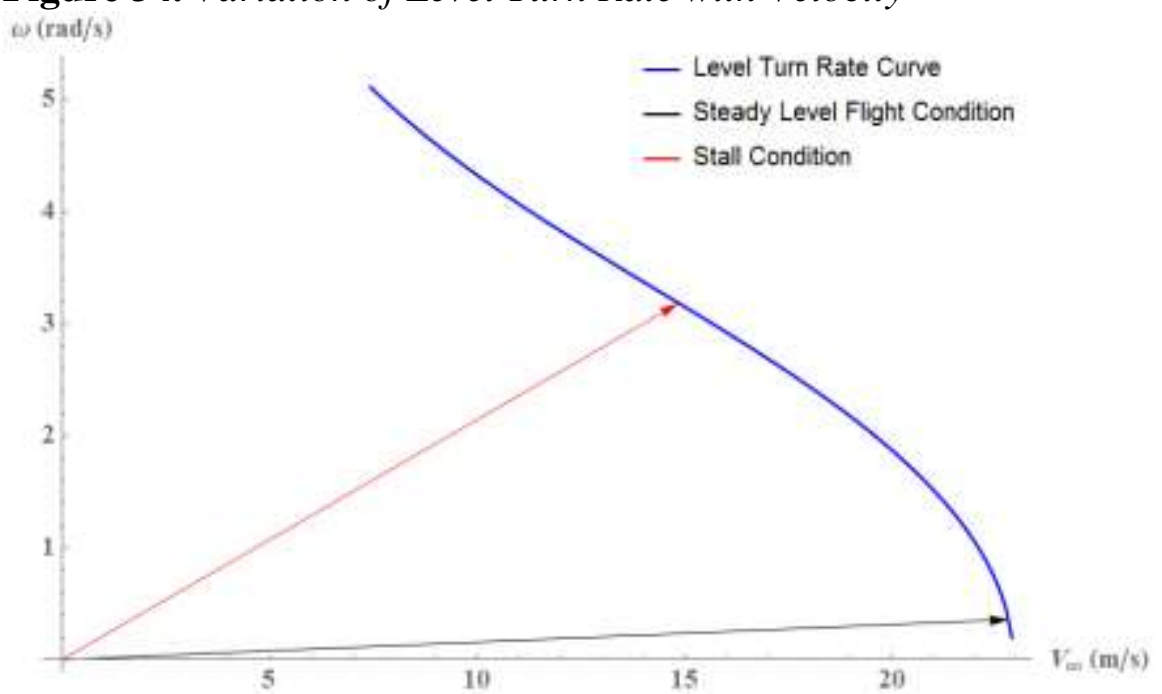

\section{Manufacturing}

A foam cutter is a machine used to cut foam using a heated metal wire. The metal wire is connected from each side to a driver motor that allows movement in two degrees of freedom. This machine has a certain language it speaks. It is called the G-Code (Massachusetts Institute of Technology, 1950s One of the simple commands is the G0X20Y100Z20A100. For the wing-like parts, GMFCProgram is used to convert the airfoil data points into G-code (1999-2012 GM Software, 2015). The link between this code and the machine itself is a program called Mach3 (2012 ArtSoft USA, 2012). 
Manufacturing processes used in building the flying wing are cutting the foam by the foam cutter machine, assembling of the parts by carbon fiber rods, black ash plate and glue, fixing the electronic components in the fuselage and connecting them together with wires, coating the flying wing with a skin, fixing the control surfaces in main body of the flying wing, and finally, cleaning the flying wing and decorating it. Photo of the final product of flying wing after finishing the manufacturing processes is shown in Figure 35.

Figure 35. Photo of the Final Flying Wing

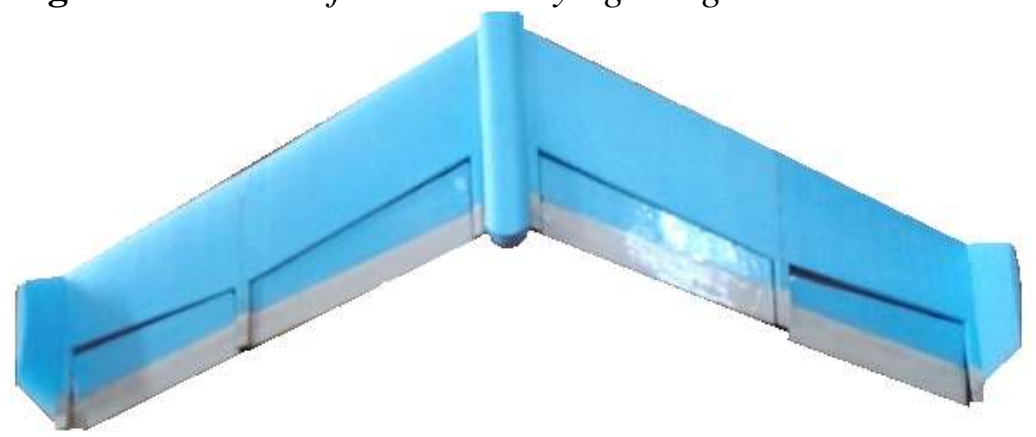

Flight Test

To ensure the success of the present flying wing design, and to prove the validity of the theorems used in design, it is important to carry a flight test. Flight tests, in general, may have many goals such as data collection, parameter acquisition ..., etc.

During the first flight test, the flying wing started its flight smoothly and started to gain altitude. Unfortunately, due to the limited test space (stadium), it had to start maneuvering early without gaining enough speed or altitude. Also, the level turn maneuver was performed at a small radius and a large banking angle which resulted in a spiral motion. This resulted in a minor damage to the flying wing which was then fixed. The second flight test went a little different. During take-off, some external disturbance, heavy side wind, affected the flying wing which resulted in a swinging motion of the flying wing and prevented the steady gain of altitude. Fortunately, this did not persist for long time and the flying wing recovered quickly and started to move in a steady manner. However, the same turn problem, which appeared during the first test, appeared again which forced an early landing and it was successful. A photo of the flying wing during actual test is shown in Figure 36. 
Figure 36. Photo of the Flying Wing during Actual Test

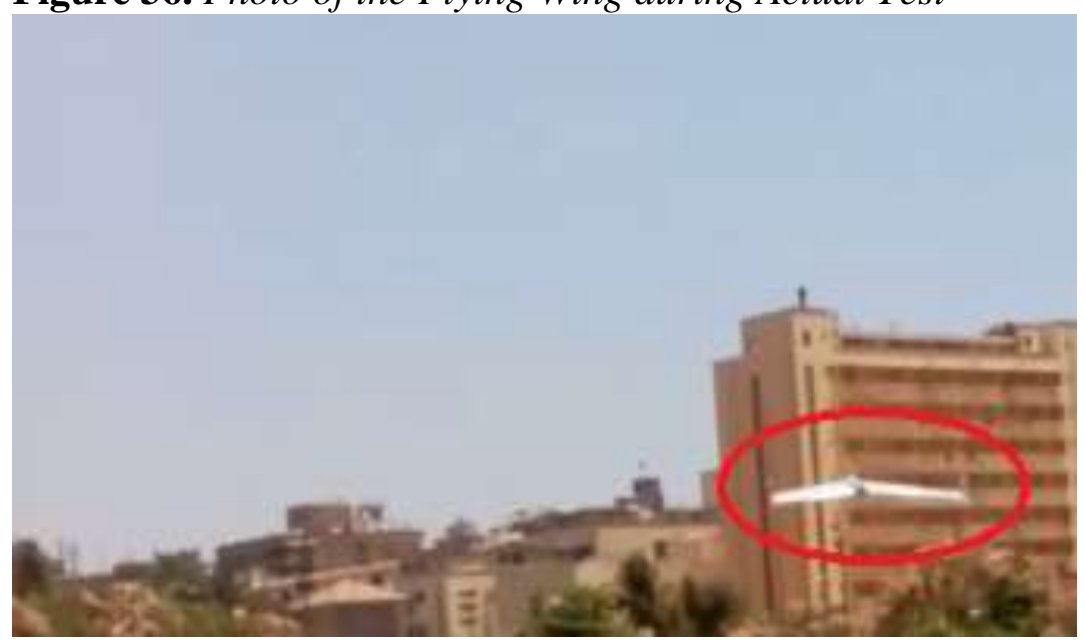

In conclusion, it can be seen that the flight tests were accepted but still has a large window for improvement, which motivates us to improve the design even further in order to achieve better results.

\section{Conclusions}

At the end, the effort, exerted in this paper, can be concluded in the following points:

- A design methodology for flying wing aircraft is introduced which differ from the traditional literature.

- Moreover, XFLR5 program is proved to be useful and reliable by comparing its results with other programs (Drela and Youngren, 2000).

- Using a wind tunnel test to verify the analysis is a necessity in design and analysis stages.

Control enthusiasts are invited to try and design an autopilot for the flying wing. As this might introduce a challenge due to the fact that flying wings are more sensitive to parameter change and have less stability compared to the conventional aircraft.

Finally, the detailed work can be checked in depth in the B.Sc. graduation project, accomplished in Cairo University (Hamada and Sultan, 2016).

\section{Nomenclature}

UAV Unmanned aerial vehicle.

CFD Computational fluid dynamics.

CAD Computer-aided design.

C.G. Center of gravity. 
AOA Angle of attack.

RC Radio-controlled.

\section{References}

Abbas, Y. and Abdelrahman, M. (2015) "Implementation of the Panel Method to the Solution of Flow around Aircraft." Bucharest, Romania: INCAS3rd International Workshop on Numerical Modelling in Aerospace Sciences, NMAS.

Abdelrahman, M. and Al-Bahi, A. (1994) "A Generalized Technique for the Inverse Simulation of Aircraft Motion along Predetermined Trajectories." AIAA Paper No 94-3523. Presented at the AIAA Atmospheric Flight Mechanics Conference, the Phoenician Scottsdale, AZ.

Anderson, J. (1998) "Aircraft Performance and Design." Published by McGraw-Hill Book Company, First Edition.

ANSYS (2015) Inc., Fluent ANSYS V16.2.0. Retrieved from www.ansys.com/.

Backstrorm, A. (1979) "The elements of tailless airplane design." EAA 1162, Frisco, TX 75034.

Dassault Systemes (1995-2012) SolidWorks Premium 2013 x64 Edition. Retrieved from www.solidworks.com/.

Drela, M. and Youngren, H. (2000) XFLR5 V6.10.04. Retrieved from www.xflr5.com/.

Hamada, A, and Sultan, A. (2016) "Design a Flying Wing." B.Sc. graduation project at Aerospace Dept., Faculty of Engineering, Cairo University.

Hussein, A., Kasem, M., Saleh, M., Saafan, M. and Zaki, M. (2010) "Flying wing Design project, African Hawk." B.Sc. graduation project at Aerospace Dept., Faculty of Engineering, Cairo University.

Massachusetts Institute of Technology (1950s) G-code First Edition [programming language].

Mohamed, E. (2016) "The Effect of Winglet on Wing Performance." Aerospace Dept., Faculty of Engineering, Cairo University.

Nelson, R. (1998) "Flight Stability and Automatic Control." Published by McGrawHill Book Company, Second Edition.

Nickel, K. and Wohlfahrt, M. (1994) "Tailless aircraft in theory and practice." Translated by Capt. Eric Brown and published by Edward Arnold.

RCfoam website (2017) "Depron and EPP Foam Suppliers." [Online]. Available at: www. rcfoam.com/depron-and-epp-foam-suppliers/blucor/ [Accessed 2016].

Roskam, J. (2003) "Airplane Design Parts I through VII." Published by Roskam Aviation and Engineering Corporation; Second Edition.

Siegmann, H. (2017) "Airfoil Database for Tailless and Flying Wings." [Online.] Available at: www.aerodesign.de/english/profile/profile_s.htm. [Accessed 2016].

Smith, L. and Campbell R. (1996) "Effects of Winglets on the Drag of a Low-AspectRatio Configuration." NASA Technical Paper 356.

Traub, L. (2011) "Range and Endurance Estimates for Battery-Powered Aircraft." EmbryRiddle Aeronautical University, Prescott, Arizona 86301 DOI: 10.2514/1.C031027.

1999-2012 GM Software, GMFC V3.90. Retrieved from www.gmfcsoft.com/, 2015.

2012 ArtSoft USA, Mach3 Software V3.043.066. Retrieved from www.machsupport. $\mathrm{com} /, 2012$. 